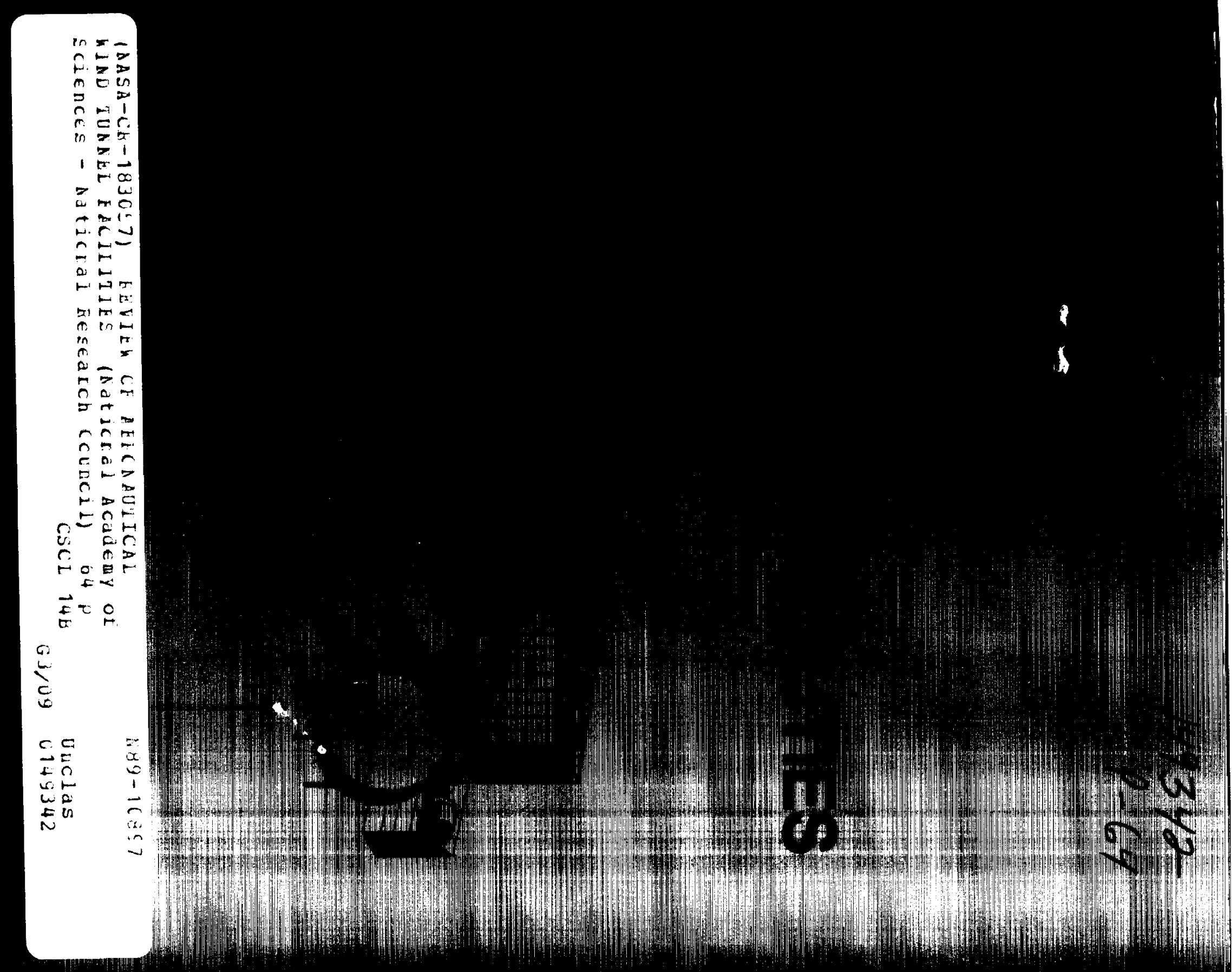




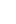

$\ldots$ 


\section{REVIEW OF AERONAUTICAL WIND TUNNEL FACILITIES}

Committee on Assessment of

National Aeronautical Wind Tunnel Facilities

Aeronautics and Space Engineering Board

Commission on Engineering and Technical Systems

National Research Council

National Academy Press

Washington, D.C. 1988 


\section{National Academy Press $\quad 2101$ Constitution Avenue, N.W. • Washington, D. C. 20418}

NOTICE: The project that is the subject of this report was approved by the Governing Board of the National Research Council, whose members are drawn from the councils of the National Academy of Sciences, the National Academy of Engineering, and the Institute of Medicine. The members of the committee responsible for the report were chosen for their special competences and with regard for appropriate balance.

This report has been reviewed by a group other than the authors according to procedures approved by a Report Review Committee consisting of members of the National Academy of Sciences, the National Academy of Engineering, and the Institute of Medicine.

The National Academy of Sciences is a private, nonprofit, self-perpetuating society of distinguished scholars engaged in scientific and engineering research, dedicated to the furtherance of science and technology and to their use for the general welfare. Upon the authority of the charter granted to it by the Congress in 1863 , the Academy has a mandate that requires it to advise the federal government on scientific and technical matters. Dr. Frank Press is president of the National Academy of Sciences.

The National Academy of Engineering was established in 1964, under the charter of the National Academy of Sciences, as a parallel organisation of outstanding engineers. It is autonomous in its administration and in the selection of its members, sharing with the National Academy of Sciences the responsibility for advising the federal government. The National Academy of Engineering also sponsors engineering programs simed at moeting national needs, encourages education and research, and recognizes the superior achievements of engineers. Dr. Robert $M$. White is president of the National Academy of Engineering.

The Institute of Medicine was established in 1970 by the National Academy of Sciences to secure the services of eminent members of appropriate profeasions in the examination of policy matters pertaining to the health of the public. The Institute acts under the responsibility given to the National Academy of Sciences by its congressional charter to be an adviser to the federal government and, upon its own initiative, to identify issues of medical care, research, and education. Dr. Samuel $O$. Thier is president of the Institute of Medicine.

The National Research Council was organised by the National Academy of Sciences in 1916 to associate the broad community of science and technology with the Academy's purposes of furthering knowledge and advising the foderal government. Functioning in accordance with general policies determined by the Academy, the Council has become the principal operating agency of both the National Academy of Sciences and the Nationsl Academy of Engineering in providing services to the government, the public, and the scientific and engineering communities. The Council is administered jointly by both Academies and the Institute of Medicine. Dr. Frank Press and Dr. Robert M. White are chairman and vice-chairman, respectively, of the National Research Council.

This report and the study on which it is based were supported by Contract No. NASW-4003 between the National Aeronautics and Space Administration and the National Academy of Sciences.

Copies of this publication are available from:

Aeronautics and Space Engineering Board

National Research Council

2101 Constitution Avenue, N.W.

Washington, DC 20418

Printed in the United States of America

Cover: NASA Ames Resesrch Center 6×6-foot supersonic wind tunnel with supporting facilities. SOURCE: National Aeronautics and Space Administration 


\section{COMMITTEE ON ASSESSMENT OF NATIONAL \\ AERONAUTICAL WIND TUNNEL FACILITIES}

RONALD SMELT (Chairman), Lockheed Aircraft Corporation (Retired) BRUCE BLAKE, Director of Research and Technology, Boeing Helicopters

SEYMOUR M. BOGDONOFF, Professor, Department of Mechanical and Aerospace

Engineering, Princeton University

RICHARD G. BRADLEY, Director, Aerospace Technology, General Dynamics

Corporation

DAVID HAZEN, Professor, Department of Mechanical and Aerospace Engineering, Princeton University (Retired)

MARTIN C. HEMSWORTH, Senior Consultant, Aircraft Engine Business Group, General Electric Company

ROBERT W. LEONARD, Director, Advanced Technology, Douglas Aircraft Company

ROBERT G. LOEWY, Institute Professor, Rensselaer Polytechnic Institute

J. LEITH POTTER, Consultant and Research Professor, Vanderbilt University

ALFRED RITTER, Senior Associate, Huntsville Operations, Booz-Allen \& Hamilton, Inc.

RICHARD S. SHEVELL, Professor, Department of Aeronautics and Astronautics, Stanford University

ROBERT H. WICKEMEYER, Chief Engineer, Aerodynamics Technology, Boeing

Commercial Aircraft Company

\section{Government Liaison Representatives}

JAMES G. MITCHELL, Chief Scientist, Arnold Engineering Development Center L. MICHAEL WEEKS, NASA Headquarters

LOUIS J. WILLIAMS, NASA Headquarters

Staff

RICHARD M. OBERMANN, Study Director

BERNARD MAGGIN, Study Director (through 12/87)

JENNIFER T. ESTEP, Administrative Secretary 


\section{AERONAUTICS AND SPACE ENGINEERING BOARD}

JAMES J. KRAMER (Chairman), Manager, Advanced Technology Programs, General Electric Company

MAX E. BLECK, President, Beech Aircraft Corporation

RICHARD G. BRADLEY, Director, Aerospace Technology, General Dynamics Corporation

BERNARD BUDIANSKY, Gordon McKay Professor of Structural Mechanics, Abbott and James Lawrence Professor of Engineering, Harvard University

ROBERT H. CANNON, JR., Charles Lee Powell Professor, Chairman, Department of Aeronautics and Astronautics, Stanford University

EUGENE E. COVERT, Professor, Head, Department of Aeronautics and Astronautics, Massachusetts Institute of Technology

W. BOWMAN CUTTER III, Partner, Coopers and Lybrand

RICHARD HEPPE, President, Lockheed-California Company

RICHARD W. HESSELBACHER, Manager, Advanced Development and Information Systems, General Electric Company

BYRON K. LICHTENBERG, President, Payload Systems, Inc.

DONALD J. LLOYD-JONES, President, American Express Aviation Center

STANLEY MARTIN, JR., Technical Director, Bell-Boeing Joint Program Office

JOHN H. McELROY, Dean of Engineering, University of Texas-Arlington

JOHN L. McLUCAS, Chairman of the Board, QuesTech, Inc.

DUANE T. McRUER, President, Systems Technology, Inc.

FRANKLIN K. MOORE, Joseph C. Ford Professor of Mechanical Engineering, Cornell University

GEORGE W. MORGENTHALER, Associate Dean for Research, College of Engineering and Applied Science, and Chairman, Department of Aerospace Engineering Sciences, University of Colorado

JAN ROSKAM, Ackers Distinguished Professor of Aerospace Engineering, University of Kansas

RICHARD S. SHEVELL, Professor, Department of Aeronautics and Astronautics, Stanford University

THOMAS P. STAFFORD, Lt. General, U.S. Air Force (Retired)

MORRIS A. STEINBERG, Consultant

ALBERTUS D. WELLIVER, Vice President, The Boeing Company

\section{ASEB Staff}

ROBERT H. KORKEGI, Director

JOANN CLAYTON, Senior Program Officer

RICHARD M. OBERMANN, Senior Program Officer

ANNA L. FARRAR, Administrative Assistant

JENNIFER T. ESTEP, Administrative Secretary

REGINA F. MILLER, Senior Secretary 


\section{Acknowledgments}

The committee extends its appreciation to the National Aeronautics and Space Administration (NASA) and Department of Defense liaison representatives on the committee, and to the industry and NASA representatives who briefed the committee and took an active part in its open discussions. The participants are listed in Appendix A. 
$-$ 


\section{Contents}

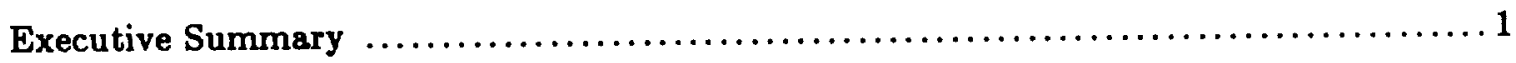

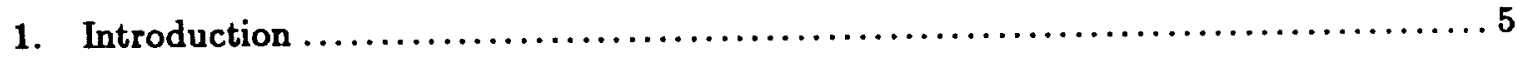

Background, 5

Approach, 7

2. Present Facilities and Their Management $\ldots \ldots \ldots \ldots \ldots \ldots \ldots \ldots \ldots \ldots \ldots \ldots, \ldots \ldots \ldots$

Wind Tunnel Maintenance and Improvement, 9

CFD and Wind Tunnel Use, 12

Committee Position on Present Facilities, 12

3. Aerospace Vehicle Programs and Their Implications for

New or Updated Facilities

Vehicle and Technology Outlook, 13

Facility Implications, 15

4. New or Updated Subsonic, Transonic, and Supersonic Facilities

Supersonic Low-Disturbance Wind Tunnel, 19

Large-Scale Acoustic and Prop Fan Facilities, 21

Subsonic Laminar Flow Development and Practical Application, 23

The Langley Vertical Flow Spin Tunnel, 25

Exhaust Nozzle Test Facilities, 26

Other Proposals for New NASA Facilities, 27

5. Hypersonic Facilities

General Discussion, 31

New or Updated Hypersonic Facilities, 32

The Role of CFD and Flight Testing, 41

Facilities for Structural Testing, 42

References. 


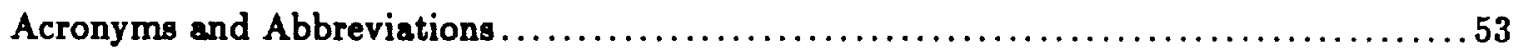
Appendixes

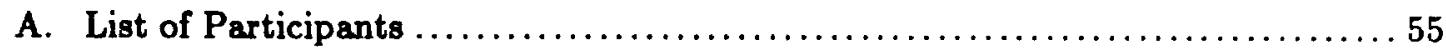

B. Committee's Statement of Task ................................... 57 


\section{List of Tables and Figures}

\section{TABLES}

3-1 Essential Technologies for Representative Aircraft Types..................... 14

4-1 The Netherlands DNW Wind Tunnel Specifications..........................22

4-2 Proposed Specifications for the Exhaust Nozzle

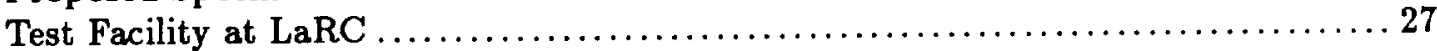

4-3 New Subsonic, Transonic, and Supersonic Facilities

Suggested by Responses to NASA Task Team Survey,

with ASEB Committee Comments..................................... 28

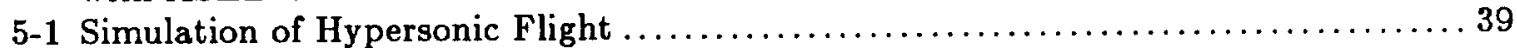

\section{FIGURES}

4-1 Comparison of wind tunnels for aeroacoustic studies $\ldots \ldots \ldots \ldots \ldots \ldots \ldots \ldots \ldots \ldots \ldots \ldots \ldots \ldots, 22$

5-1 Typical manned lifting entry trajectories and

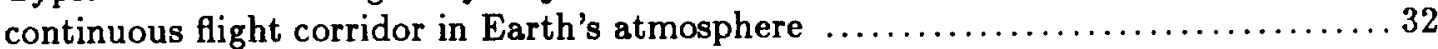

5-2 Equilibrium reservoir conditions necessary for

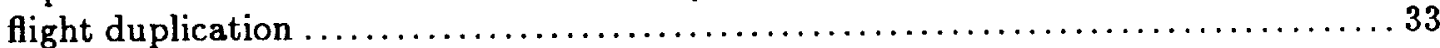

5-3 Schematic and operational characteristics of the Langley

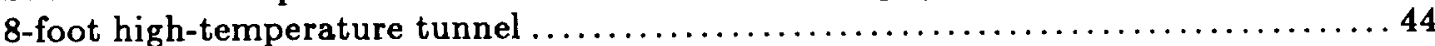

5-4 B-2 test facility structural test of NASP airframe section $\ldots \ldots \ldots \ldots \ldots \ldots \ldots \ldots \ldots, 45$

5-5 Cryogenic Structures Test Apparatus .....................................

5-6 Liquid Hydrogen Structural Test Facility testing complex $\ldots \ldots \ldots \ldots \ldots \ldots \ldots \ldots \ldots 48$ 



\section{Executive Summary}

The nation's aeronautical wind tunnel facilities constitute a valuable technological resource and make a significant contribution to the global supremacy of U.S. aircraft, both civil and military. These facilities are numerous and have diverse capabilities; they are owned and operated by the aeronautical industry, the academic community, and the aeronautical laboratories of the U.S. government, chiefly those of the National Aeronautics and Space Administration (NASA), the U.S. Air Force, and the U.S. Navy.

The NASA aeronautical wind tunnel facilities serve both research and development needs. The smaller tunnels are engaged primarily in fluid flow research, while the major tunnel facilities have a dual role in supporting research and in supporting industrial development of new aerospace vehicles. The demand for testing in wind tunnels and related facilities is expected to remain high and may even increase because of the additional need to verify or extend computational fluid dynamics (CFD) codes. As a result, the health of the entire national aeronautics effort is closely linked to the health of the NASA (and Department of Defense) facilities.

At the request of NASA, the National Research Council's Aeronautics and Space Engineering Board organized a committee to review the state of repair, adequacy, and future needs of major aeronautical wind tunnel facilities in meeting national goals.

The committee identified three main areas where actions are needed to sustain the capability of NASA's aeronautical wind tunnel facilities to support the nation's aeronautical research and development activities: tunnel maintenance and upgrading, productivity enhancement, and accommodation of new requirements (particularly in hypersonics). This report addresses each of these areas and presents the committee's recommendations for appropriate actions.

\section{FACILITY MAINTENANCE AND UPGRADING}

The ASEB committee shares the concern of the NASA in-house Wind Tunnel Study Task Team over the deterioration and increasing obsolescence of some of NASA's most valuable aeronautical wind tunnel facilities. While neither the NASA Task Team nor the committee recommends retiring any of the major facilities, three actions are suggested to improve the situation. 
First, common experience-based standards for the maintenance and improvement of major experimental facilities should be established. Rigorous inspection and maintenance based on these standards should be followed.

Second, a mechanism should be put in place to speed up the authorization of unexpected repairs when the unique capabilities of the facility are in demand. Moreover, funding practices and procedures should be developed that will lead to more expeditious responses to both expected and unexpected requirements for maintenance, repair, and modification of facilities. As a specific example of a desired output, replacement of the cracked pressure shell of the Ames Research Center 12-foot tunnel should be made a high priority.

Third, wind tunnel components, particularly those related to wind tunnel control and data handling, should be updated periodically. To facilitate this updating, it is suggested that NASA accept a lifetime of at most ten years for wind tunnel control, data retrieval, and data analysis equipment. To improve the prospects for funding such improvements, it is proposed that control and data handling equipment be carried as an independent item in each NASA center's budget and not identified with R\&D funding.

\section{PRODUCTIVITY ENHANCEMENT}

Another concern of the committee is that the productivity of test work in NASA test facilities is substantially lower than that of work in similar facilities in industry and other government laboratories. The committee believes that the principal causes of this lower productivity are inadequate staffing, obsolescent data processing systems, and inefficient model buildup, installation, and removal.

Inadequate staffing (in terms of numbers, not quality) is a problem because it can cause long delays in test data analysis and reporting. The commitee recommends that while it is often better to reduce staffing at low-use facilities than to mothball the facility, sufficient experienced staff should be maintained to provide on-line data for those tests that are conducted.

Obsolescent data acquisition and processing equipment makes it difficult to provide corrected data during the conduct of tests; it also delays the availability of both preliminary and final reports. The committee reiterates its recommendations for the upgrading of that equipment.

A number of industrial and government facilities have been able to force significant increases in the amount of data obtained per occupancy hour by means of revised model handling methods and new test section rigs and procedures. The committee recommends that NASA review the methods employed in industry and DoD facilities and, where appropriate, develop them further for application to individual NASA facilities.

\section{ACCOMMODATION OF NEW REQUIREMENTS}

National goals in aeronautics, including those in both the civilian and military sectors, fall into three broad categories: (1) goals related to subsonics and transonics, in which a new generation of superior aircraft is envisioned; (2) goals related to supersonics, in which long-distance efficiency and environmental compatability are stressed; and (3) goals related to transatmospherics, in which the global issues of aerospace leadership and national security are addressed. The success of future advanced aircraft, missile, and space systems in satisfying these goals will depend upon both evolutionary and revolutionary technological 
advances in areas including, but not limited to, high-performance turbine engine propulsion; supersonic ramjet propulsion; multicycle turbo- and ramjet propulsion; aerpropulsion integration; hypersonic aerothermodynamics; high lift; laminar flow and drag reduction; vortex control; thrust management and vectoring; reduced observability; lightweight, hightemperature materials and structures; and improved thermal protection systems. These technological advances will require adequate capability for the ground-based testing and simulation of real flight conditions, to be used in combination with computational fluid dynamics (CFD) and selective flight testing.

After examining the existing national aeronautical facilties' capabilities, the committee has concluded that additional facilities are needed to handle the new requirements for testing. The need is most pronounced in the area of hypersonics, but some new facilities also are needed to support subsonic, transonic, and supersonic research and development activities.

\section{Subsonic/Transonic/Supersonic Facilities}

The committee recommends that the following facilities (listed in descending order of priority) be developed by NASA to support testing in the subsonic, transonic, and supersonic flight regimes:

1. A supersonic low-disturbance wind tunnel for studies of boundary layer transition, mixing, turbulent boundary layers, and the validity of data from conventional wind tunnels.

2. A large-scale acoustic and prop fan facility for low-speed and high-subsonic/transonic investigation of rotors and prop fans, if continued reliance on the Deutsch Niederlandischer Windkanal (a facility in the Netherlands) is deemed unacceptable by the U.S. government.

3. A large vertical flow spin tunnel for exploring spin characteristics of advanced configurations (if modification of the existing Langley Research Center facility proves undesirable from a benefit/cost standpoint).

4. An improved exhaust nozzle test facility to be used to obtain performance data on exhaust systems up to the very high pressure ratios (and representative Reynolds numbers) associated with high-Mach-number operation.

\section{Hypersonic Facilities}

While NASA's existing hypersonic facilities can make important contributions to materials and structures research, limited propulsion system research, and hypersonic CFD code validation research, the committee believes that there is an urgent requirement for additional hypersonic facilities. One of the most pressing needs is for facilities that enable efficient test programs to be conducted for the development of integrated configurations of hypersonic aerospace vehicles. These facilities should allow tests under conditions that more adequately simulate full-scale flight than do the continuous flow wind tunnels currently available.

The committee recommends that the following actions be taken with respect to new hypersonic facilities:

1. NASA should consider building a new, quiet hypersonic facility reaching Mach 10 if it does not prove possible to modify an existing tunnel to adequately represent boundary layer and flow conditions.

2. An electric arc-heated, continuous-type tunnel design should be considered for hypersonic configuration development at Mach numbers of 10 and above. This design concept 
requires further research and development work before a final decision on construction can be made.

3. Continuing research and selective small-scale development should be directed at several advanced techniques, such as magnetohydrodynamics, for providing flow conditions suitable for testing at the higher velocities of interest.

4. NASA centers' structures test facility proposals should be brought together in a central NASA plan for long- and short-term facility actions. The committee feels that each of NASA's centers involved in materials and structures technology research should have facilities for hypersonic materials and structural tests of specimens ranging in size up to small structural components. Specifically, NASA should proceed with

- Construction and activation of the Liquid Hydrogen Structural Test Facility at the Ames Research Center's Dryden Flight Research Facility, and

- Construction and activation of the Langley Research Center-proposed Thermal Acoustic Loads and Fatigue Research Laboratory, if such a step is supported by the current examination of test facility requirements that NASA has initiated with five airframe companies.

In addition, NASA should complete the reactivation of the Lewis-Plum Brook Station test facilities to support near-term development work.

Finally, the committee notes that no ground-based facility exists, or can be expected to be built in the near future, of sufficient size to test a large model of an aerospace vehicle with engines operating at any hypersonic Mach number. Furthermore, CFD is not likely to provide answers over all hypersonic Mach numbers of interest. Thus, there will continue to be a requirement for flight testing as a tool in design validation. 


\section{1 \\ Introduction}

At the request of the National Aeronautics and Space Administration (NASA), the National Research Council's (NRC's) Aeronautics and Space Engineering Board (ASEB) organized a committee (the Committee on Assessment of National Aeronautical Wind Tunnel Facilities) to review the state of repair, adequacy, and future needs of major aeronautical wind tunnel facilities in meeting national goals (Aeronautical Policy Review Committee, 1987). This report gives the findings and recommendations of the NRC-ASEB committee.

The committee was to concentrate on NASA facilities, taking into consideration other government and industry facilities, as appropriate. It was to identify those actions required to provide the future capabilities considered most important.

It is necessary to clarify terminology before proceeding further. The ASEB committee has taken the view that the term wind tunnel in the committee's charge refers not only to conventional wind tunnels but also to related aerospace experimental laboratory facilities in general. The term facilities, as used throughout this report, includes wind tunnels, aeroballistics ranges, shock tubes, counterflow devices, static test stands, and other means of gathering experimental data.

\section{BACKGROUND}

To appreciate the concerns that prompted the committee's study of the major national aeronautical facilities, a brief review of the vital role of these facilities in aerospace research and development (R\&D) is appropriate. There are many aeronautical facilities with diverse capabilities in the United States; they are owned and operated by the aeronautical industry, the academic community, and the aeronautical laboratories of the U.S. government, chiefly those of NASA, the U.S. Air Force (USAF), and the U.S. Navy. The system by which these facilities are interlinked has been refined over many years, and is a significant factor contributing to the global supremacy of U.S. aircraft, both civil and military.

The major airplane development companies in the United States possess their own wind tunnels, with the maximum capabilities that their corporate financial resources will permit. These in-house facilities furnish much of the design data in the early stages of new

* See Appendix B for the Committee's Statement of Task. 
development. As aircraft performance and complexity have increased, the amount of wind tunnel data required for design has escalated. The companies now rate high productivity as one of the capabilities that must be built into their wind tunnels for development work, along with the more familiar tunnel performance requirements (size, Mach number, Reynolds number, and so forth). Productivity has, in fact, been greatly increased by recent advances in electronic instrumentation, data reduction equipment and techniques, and wind tunnel and model control techniques. In contrast, university wind tunnels, and some of the smaller NASA wind tunnels, are engaged primarily in fluid flow research projects and have no special provisions for high productivity.

The major U.S. government wind tunnel facilities are some of the world's largest and most powerful aeronautical facilities, uniquely capable of approaching full-scale flight conditions of the many modern aerospace vehicles. It would be prohibitively expensive for any single aerospace corporation, even the nation's largest, to duplicate one of these facilities for its own development work. During World War II, the practice evolved of carrying new aircraft development as far as possible using the in-house facilities of the company and then following this up with design verification by testing the most critical features in the appropriate National Advisory Committee on Aeronautics (NACA) facilities, at conditions much closer to those of full-scale flight. That practice has continued, and proprietary testing is done on a fee basis.

The major facilities fulfill an essentially developmental role, extending new design verification to areas otherwise unattainable in industrial or university wind tunnels. But these new areas also offer the possibility of new and valuable programs for the NASA research engineers and scientists. The major NASA facilities thus have a dual role, and wind tunnel occupancy time is shared between those in NASA performing research and those in the aerospace industry testing new development programs. As might be expected, the distinction between the tests performed by the two groups can often become blurred, as when a development test of a new design reveals a problem that stimulates research or, conversely, when research results can be applied immediately to the benefit of a new project.

These arrangements for sharing facility time have existed since the days of NASA's predecessor, NACA. After the end of World War II, they were formalized when new facilities were added at both NACA and USAF aeronautical laboratories under the Unitary Plan. Similar plans for joint use of a nationally provided facility for research and industrial aircraft development have been adopted by those nations in Western Europe having strong aeronautical activities, supplemented in their case by international agreements when development projects are undertaken in conjunction with other countries. In addition, government facilities in Western Europe have the specific responsibility to aid in the development of domestic aircraft.

The NASA and Department of Defense (DoD) aeronautical facilities, serving both $R \& D$ needs in this manner, are clearly the most valuable aerodynamic ground-based testing resource in the Western world. Attempts have been made to assign a dollar value to these resources; for example, the replacement value of the facilities themselves is assessed at several billions of dollars. Such an assessment, however, does not recognize the extent to which these facilities have now become an essential element in the operation of the entire aeronautical industry in the United States. Replacement of one of them, in the event of failure, would require a reconstruction period of at least 5 , and more likely 10 , years; the financial impact upon the industry of such a hiatus in its development efforts would likely be much greater than the facility replacement value. In short, the health of the entire national aeronautical development effort is closely coupled with the health of the NASA and DoD facilities. 


\section{APPROACH}

The Committee on Assessment of National Aeronautical Wind Tunnel Facilities consisted of individuals with industrial and government experience in aerospace technology design and development including the design, development, and utilization of aeronautical facilities. The committee's plan, in response to the objectives identified by NASA, included the following:

- Assessing the expected national demand for testing in terms of types of facilities and the extent of testing required, while being cognizant of the influence of advances in computational methods on wind tunnel testing.

- Reviewing NASA, other government, and industry assessments of the adequacy of major national aeronautical facilities to meet projected demand for testing. The review was to consider both the need for rehabilitation of existing facilities and the justification for new facilities in order to provide test conditions not obtainable in present facilities.

- Assigning priorities to various aerospace facility actions in broad categories such as "critical," "very important," "moderately important," or "not useful."

Prior to the formation of the ASEB committee, NASA established the in-house Wind Tunnel Study Task Team to examine the conditions of its major aeronautical wind tunnel facilities with respect to productivity, maintenance, and needed upgrading, as well as requirements for new facilities to support the development of projected aerospace systems (Wind Tunnel Study Task Team, National Aeronautics and Space Administration, 1987). The report of the NASA Task Team was available to the present ASEB committee and was supplemented by a large amount of information from NASA, DoD, and industrial sources.

The committee held three 2-day meetings, as follows: June 11-12 and July 21-22, 1987, in Washington, D.C., and October 27-29, 1987, at the NASA Ames Research Center, Moffett Field, California. During these meetings, the committee was briefed by the NASA Task Team on its study and reviewed the study itself. The committee also was briefed by NASA, DoD, and industry representatives on hypersonics technology needs and facility implications. Finally, the ASEB committee members presented and discussed their views on specific research and technology developments and facility implications, and the committee independently developed the findings and recommendations contained in this report. 
- 


\section{Present Facilities and Their Management}

In response to a number of concerns, NASA management organized the in-house Wind Tunnel Study Task Team, with both industry and government members, to examine the conditions of the major NASA wind tunnels. This team completed an intensive examination of the facilities at the NASA centers and collected comments from the user companies throughout the U.S. aeronautical industry. In their formal report of their findings (Wind Tunnel Study Task Team, National Aeronautics and Space Administration, 1987), the Task Team sounded a clear signal of concern over the present conditions of some of NASA's most valuable development facilities. It would be redundant to repeat here the details of their report; the present committee, charged by the ASEB to make a broader review of NASA's situation, endorses both the NASA Task Team's expression of concern and their recommendations for urgent remedial action. The committee has attempted to go more deeply into the basic factors which have resulted in the present situation and how they could be corrected to bring NASA's already major contribution to aeronautical development up to its full potential.

\section{WIND TUNNEL MAINTENANCE AND IMPROVEMENT}

In its report, NASA's in-house Task Team called attention to the age of most of the major NASA wind tunnels (the average age is 30 years, the maximum is 57 years), an observation which might incorrectly be interpreted as a recommendation for retirement of some of the facilities. In fact, there was no recommendation from the NASA Task Team to retire any one of the major facilities on account of age, and after studying the situation independently, the ASEB committee came to the same conclusion. The committee did, however, identify at least three processes which contribute to a degraded capability at some of NASA's wind tunnel facilities. Since these processes give rise to quite independent recommendations to NASA's engineers and management, they are discussed in separate paragraphs below.

The first of the processes is conventional, predictable deterioration, combatted primarily by a rigorous inspection and maintenance plan and by preprovisioning of spare parts at known critical points. The process, as applied to aircraft operations, is very familiar to the USAF and the commercial airlines. However, a better model for NASA wind tunnel 
operations can probably be found in the maintenance procedures for the large electrical power-generating stations, many of which are older than the NASA facilities and are operating on more severe schedules.

Reports indicate that NASA laboratories vary significantly in their maintenance procedures and that tight funding has led to deferred maintenance in some areas. The committee recommends that operators of major NASA and DoD wind tunnels pool their maintenance experience and compare it with the pool of experience from roughly similar commercial plants. The objective is to establish a common maintenance standard, backed by experience, which thus would be much less vulnerable to funding exigencies.

A second process involves a requirement for unexpected repairs, usually resulting from faulty engineering decisions during facility construction or operation. The current problem with the pressure shell of the Ames Research Center (ARC) 12-foot tunnel is a good example. Although designed to operate at a maximum pressure of 6 atmospheres, cracking of the shell under pressure has now reached the point where operation at any positive gage pressure is dangerous, and a new shell is required utilizing material and welding techniques adequate for the repeated stress and corrosion conditions. The resulting unavailability of a high-Reynolds-number test capability at Ames is particularly unfortunate at the present time.

As new facilities operate in unfamiliar areas of temperature and pressure (the National Transonic Facility at the Langley Research Center is the latest example) with differing working fluids, more frequent incidents can be expected, requiring early modification actions. The NASA funding process for facility repair is ill-prepared to handle emergencies of this kind, as discussed in more detail in the NASA Task Team report (Wind Tunnel Study Task Team, National Aeronautics and Space Administration, 1987, pp. IV-16 to IV-18). The present approval process results in a delay of several years in realizing the benefit of a major facility investment, quite apart from the further unseen cost of technological delay across the industry. The problem is built into the approval procedures for items proposed for NASA construction of facilities (C-of-F) funding, which do not differentiate between a completely new wind tunnel concept and the necessary repair of an existing wind tunnel (if the repair is estimated to cost more than $\$ 750,000$ ).

The NASA Task Team has highlighted the ARC 12-foot tunnel problem and recommended replacement of the shell as a high-priority item. The committee strongly endorses this recommendation and would also like to see a mechanism put in place to speed up the authorization of repairs when, as in the case of the ARC 12-foot tunnel, the unique capabilities of the facility are in great demand by the aircraft industry and the research community and the facility has previously had full federal approval. The committee also notes that the use of a heavy gas (such as Freon 12) as an alternate working fluid in the ARC 12-foot tunnel could increase test Reynolds numbers by a factor of 3 . However, the environmental impact of such a step would need to be assessed before proceeding.

The third, and most important, of the processes contributing to a degraded capability at some NASA wind tunnels is delayed updating of facility equipment, particularly in the areas of wind tunnel control and data handling. During the lifetime of a facility, there typically are major technical advances made in the area of aeronautics that it serves, and equally significant changes in the technologies that it employs to derive its results. Advances in aerodynamics, which have widened the flight envelope and required a finer tuning of characteristics, have led to a great increase in the required number and accuracy of data points. The wide use of computational fluid dynamics (CFD) in design has led to additional test requirements aimed at validation of the computational models. Fortunately, these increased data demands have been accompanied by great improvements in the speed and 
accuracy of data handling-both measurement and reduction (analysis); the development of digital electronics and computers has also permitted major improvements in wind tunnel and model control during testing.

This increase in demand for data has also focused attention on unproductive wind tunnel occupancy time. In the past, the process of mounting, calibrating, adjusting, and finally removing the wind tunnel model typically expended the majority of the allocated occupancy hours. Starting around 1975, wind tunnel operators at the USAF's Arnold Engineering Development Center and in industry have been able to force significant increases in the amount of data obtained per occupancy hour by means of revised model handling methods and new test section procedures and rigs. In addition, the data reduction systems have been updated.

The productivity of test work in NASA facilities has been observed to be substantially lower than that in similar facilities in industry and other government laboratories. It is difficult to be quantitative in this assessment; estimates of experienced engineers placed productivity in NASA facilities at $\mathbf{5 0}$ to $\mathbf{7 0}$ percent of that at non-NASA facilities. The principal causes for this lower productivity are seen to be inadequate staffing, lack of modern controls and on-line data processing, and inefficient handling of models:

Inadequate Staffing - Low productivity is due to the small number of personnel available at facilities, not the quality or motivation of the personnel.* A major problem, for example, is that the limited available staff must usually go on to other work when tests are completed, which causes long delays in test data analysis and reporting. Preliminary data are typically not available for 2 to 3 months and final data are not available for 6 to 24 months; in an industrial facility, preliminary data are usually available in a few minutes and the final report is available in a few weeks. While it is often better to reduce staffing at low-use facilities than to mothball the facility, sufficient experienced staff must be maintained to provide on-line data for those tests that are conducted.

Data Handling-Another major cause of lower productivity in most NASA facilities is the lack of modern data acquisition and on-line data processing and analysis equipment to provide corrected data as the tests progress, and thus provide results and guidance as the test plan is being executed. Modern data handling capability also contributes importantly to the early availability of both preliminary and final reports.

Handling of Models-Finally, important improvements in productivity can be provided with better model preparation facilities, quick insert capabilities, and workable provisions for test section isolation for pressurized facilities.

It is essential that all members of the decision-making chain, through NASA and Congress, recognize that some essential elements of wind tunnels, notably the control, data retrieval, and data analysis equipment, have a much shorter lifetime than do the basic structure and machinery. The committee recommends acceptance of a lifetime of 10 years at most for those elements. It is evident that NASA has always recognized the special nature of such instrumentation items, for its funding conventions do not include them in the C-of-F budget. They are furnished separately as part of a NASA research center's R\&D budget. Unfortunately, from the point of view of updating the facility, this puts the center director in a difficult position. The director has been selected for his/her interest in R\&D and is being asked to dilute this emphasis to update the facilities. There must be a powerful compulsion to defer such updating for as long as possible. Therefore, funding for updating

\footnotetext{
* The committee does note, however, that there is a shortage of trained personnel in hypersonics and that a continuing flow of talent needs to be developed.
} 
the control and data handling equipment should be an independent item in the center's budget that is not identified with R\&D funds.

Next, the committee recommends that NASA should focus attention on increasing the productivity of its major wind tunnel facilities. The methods employed in industry and USAF facilities should be reviewed and further developed by NASA staff to be applied to individual NASA facilities. Funding can then be applied, as available, to a broad updating program, on a priority basis, to meet the expected future demand for wind tunnel time.

\section{CFD AND WIND TUNNEL USE}

Another area discussed by both the NASA and ASEB committees was the influence of CFD on the future need for wind tunnels. Existing work has shown clearly that there is insufficient basic information on turbulence and the process of transition at high Reynolds numbers, and that researchers must depend on the wind tunnel for data to permit the modeling of these processes by CFDs. The status of CFD is described in a number of recent publications (Dwoyer et al., 1987; National Research Council, 1983, 1986), and can be summarized by saying that it appears that wind tunnel activities will be significantly increased over at least the next 10 to 15 years to assist in CFD development. The nature of wind tunnel experimentation will also change, to permit more accurate evaluations of flow characteristics at high Reynolds numbers. However, when the National Transonic Facility is modified to overcome its start-up problems and the ARC 12-foot tunnel is recommissioned, the NASA complex of wind tunnels will be adequate for the task, except for the problems associated with duplication of flight boundary layer transition and related phenomena, and any aerothermal problem where viscous effects are important.

\section{COMMITTEE POSITION ON PRESENT FACILITIES}

The NASA Task Team, on the basis of facility user surveys that involved 17 industry and 5 other government groups, concluded that none of the major facilities are candidates for closing. The ASEB committee is in essential agreement with the general findings and recommendations of the NASA Task Team, with the notable exception of the feasibility of a large, integrated hypersonic facility. The committee does not believe such a facility is feasible in the near future. However, it is believed that each specific existing facility should receive close scrutiny before reactivation or updating actions are taken. For example, the Task Team referred to the hypersonic complex as a singular, major facility. The committee suggests that each wind tunnel and aeroballistics range making up this complex be examined individually.

The committee believes that NASA's management and staff are sensitive to the issues addressed here. In the committee's view, immediate attention and action should be given to the above facility matters if the United States is to maintain its lead role in aeronautics. 


\section{3 Aerospace Vehicle Programs and Their Implications for New or Updated Facilities}

The committee's second task was to review the adequacy of major national facilities to meet projected future test requirements. Fortunately, some recent projections of future national aerospace goals are available to assist in this task. In February 1987, the Office of Science and Technology Policy released a report, "National Aeronautical R\&D GoalsAgenda for Achievement" (Aeronautical Policy Review Committee, 1987), that established a cohesive strategy and action plan to achieve national goals in aeronautics, and thus enable the United States to remain a viable competitor in the world aviation marketplace.

The goals, which include both the civil and military sectors, apply across the flight spectrum and fall into three broad categories: (1) subsonics, in which a new generation of superior aircraft is envisioned; (2) supersonics, in which long-distance efficiency and environmental compatibility are stressed; and finally, (3) transatmospherics, in which the global competitive issues of aerospace leadership and national security are addressed. These broad goals stem from the vehicle classes identified in studies by the Aeronautics and Space Engineering Board of the National Research Council $(1984,1985)$ and in the USAF's recent classified Forecast II study of possible aeronautical technology and vehicle advances by the year 2000. Table 3-1 from an NRC report (1985), presents some of the essential technologies for the design and development of the aircraft classes discussed in that study.

\section{VEHICLE AND TECHNOLOGY OUTLOOK}

In the above-mentioned assessments, future programs and supporting technologies were identified for a wide range of vehicle operating conditions for both military and commercial vehicles. Representative vehicle types for the subsonic, supersonic, and hypersonic/transatmospheric flight regimes are as follows:

- Subsonic-For the military, a new strike fighter, an intertheater vertical and short takeoff and landing (VSTOL) transport, a multirole global range aircraft, and a long-haul airlifter; for the commercial sector, advanced short-, medium-, and longrange transports as well as commuter aircraft. Projected technology developments related to rotary wing aircraft were judged to satisfy both DoD and civilian needs. 
TABLE 3-1 Essential Technologies for Representative Aircraft Types

\section{Military Aircraft}

Subsonic strike aircraft

Reduced observability

Aeropropulsion integration

Reliable engines

Supersonic STOVL ${ }^{a}$

Thrust management and vectoring

Integrated concepts and operations

Engine materials

Advanced fighter

Supersonic propulsion

High-temperature materials and structures

Supersonic high $\mathrm{L} / \mathrm{D}^{b}$ and maneuvering lift

Low observability

\section{Hypersonic Vehicles ${ }^{c}$}

Multicycle turbo and ramjet propulsion

Integrated avionics

Controls

Cryogenics

Materials and thermal protection

Lightweight structures

Transatmospheric Aircraft

Propulsion

Aerodynamics/structures

Thermal protection systems

Lightweight structures

Materials

Controls and integrated avionics

\section{Transport Aircraft $^{d}$}

Subsonic transport aircraft

Propulsion systems

Drag reduction

Materials and structures

High lift

Flight control (low speed)

Noise reduction (civil)

Commuter aircraft

Propulsion systems

Laminar flow

Supersonic transport aircraft

Propulsion systems

Lightweight/temperature-tolerant materials/structures

Noise and sonic boom reduction

\section{Rotorcraft}

Noise/vibration reduction

Drag reduction

Control/stabilization

New propulsion system concepts

System validation

\section{Extremely-High-Altitude Aircraft \\ Energy storage and energy system integration \\ Ultralight structures}

${ }^{a}$ Short takeoff and vertical landing.

$b_{\text {Lift over drag. }}$

$c^{c}$ Airplanes and missiles.

${ }^{d}$ Civil and military; short- and long-haul.

SOURCE: National Research Council (1985). 
- Supersonic-For the military, the advanced fighters, the advanced technology bombers, and VSTOL tactical aircraft; for the commercial sector, a new generation of commercial transports.

- Hypersonic/Transatmospheric-The National Aerospace Plane (NASP) program, a joint NASA-DoD program, designed to help satisfy long-range military system technology requirements and to spearhead the technology for commercial transatmospheric transports for the next century. In addition, for the military, hypersonic interceptor-reconnaissance vehicles, long-range air-to-air missiles, long-range boostglide vehicles, hypervelocity weapons, extremely-high-altitude aircraft, reusable aeroassist orbital transfer vehicles, advanced heavy-lift space vehicles, advanced reentry systems, tactical missile systems, and strategic defense missiles.

A few additional comments on some specific technical challenges of hypersonic flight are in order. Some spacecraft envisioned for the future will maneuver at hypersonic Mach numbers and be designed to closer performance margins than current systems; the hypersonic segments of their missions thus will be vital considerations in their design. Atmospheric braking, for example, has many advantages over retro-rocket braking. It is very likely to be the preferred braking mode for future spacecraft intended to explore the large planets and then to return to Earth. Similarly, space vehicles that must perform orbit changes may use aerodynamic forces for orbit adjustment rather than direct rocket power.

Furthermore, the entire class of transatmospheric vehicles, encompassing both veryhigh-speed intercontinental commercial transports (the "New Orient Express") and singleorbit military bomber or reconnaissance vehicles, will be able to maneuver for flexibility in choosing a landing site and be equipped with reusable thermal protection systems for quick turnaround. The NASP program is a technology development program aimed at developing such capabilities, focusing on single-stage-to-orbit and horizontal takeoff capabilities. This introduces the concept of an air-breathing power plant that can accelerate the vehicle to high Mach numbers, using updated ramjet and scramjet technologies. The most obvious of the technical challenges to be overcome is the development of vehicle net thrust. At hypersonic Mach numbers, the entire forward fuselage must act as a compressor for the engine, and the entire aft fuselage must act as a thrust nozzle. Also very challenging are the means by which thermal protection, thermoaeroelastic stability and control, and structural integrity will be achieved throughout the large operating envelope of these vehicles.

The success of these aircraft, missile, and space systems will depend upon both evolutionary and revolutionary advances across a very broad spectrum of technological activities including, but not limited to, the following: high-performance turbine engine propulsion; supersonic ramjet propulsion; multicycle turbo- and ramjet propulsion; aeropropulsion integration; hypersonic aerothermodynamics; high lift; laminar flow and drag reduction; thrust management and vectoring; reduced observability; lightweight, high-temperature materials and structures; and improved thermal protection systems. The wind tunnels and related facilities necessary to support these advances are discussed in the following section.

\section{FACILITY IMPLICATIONS}

The NASA Task Team and the members of industry, DoD, and NASA who responded to its questionnaires were generally aware of the projections regarding vehicles and technologies outlined above. Their responses included a number of proposals for new facilities to support these future developments. Chapters 4 and 5 detail the committee's recommendations after discussion of these responses, and indicate the relative priority that the committee associated with each item. In making these assessments the committee assumed a steadily increasing 
utilization of CFD in the development process. In addition, although the committee's deliberations were specifically directed at NASA facilities, it assumed that the present combination of NASA, DoD, university, and industrial technical capabilities and facilities would continue. Most importantly, the committee postulated that trained, experienced professional and technical staff would be available in adequate numbers.

The committee concurs with the NASA Task Team that the extensive NASA facilities for subsonic, transonic, and supersonic development, maintained and upgraded as discussed in Chapter 2, can meet most of the testing requirements of the near future. The few additions required to meet "National Aeronautical R\&D Goals" (Aeronautical Policy Review Committee, 1987) in these speed ranges are reviewed in detail in Chapter 4.

The hypersonic speed range has been singled out for special review in Chapter 5, since the goals of air-breathing propulsion at hypersonic speeds and a single-stage-to-orbit capability require a high degree of integration of the engine and airframe, with resulting inseparable aerodynamic characteristics to be understood. Resolution of this aerodynamics problem is beyond the reach of the nation's current hypersonic facilities. Since 1950, over 20 hypersonic facilities for aerodynamic testing and at least 5 for propulsion testing were built in the United States. However, many of the hypersonic facilities have been mothballed or scrapped during the last two decades, a period of low interest and minimal funding for hypersonic research and technology. Of the current facilities, the majority are owned by NASA, but there are additional productive facilities in DoD laboratories and at a few universities.

The existing hypersonic facilities receive only brief mention in the report of the NASA Wind Tunnel Study Task Team, in contrast to its detailed treatment of NASA's lowerspeed wind tunnels. The report puts forward a requirement for "a real-gas hypersonic wind tunnel capable of testing complete airframe configurations at reasonably large scale," and proposes an early decision be made regarding the construction of such a facility. This is not a practical proposal, at the present state of technology. The total temperature and pressure ahead of the nozzle, if the tunnel construction follows current practice, increases to values in excess of $10,000 \mathrm{~K}$ and 10,000 atmospheres as the typical flight corridor of an air-breathing vehicle is traversed and orbital speed is approached. (See Figure 5-2 in Chapter 5 for details.) Present capabilities would limit test conditions to the very low end of the flight corridor, up to Mach numbers of about 8 to 10. In short, above this Mach number range in the flight corridor of an air-breathing vehicle, it is not possible with present technology to combine correct simulation of the combustion process in the propulsion unit and correct aerodynamics of the flow outside.

The testing procedure being adopted for the NASP program may therefore become the prototype for future test programs in the hypersonic regime. This involves tests in existing hypersonic propulsion facilities at the lower end of the flight corridor; above this limit hypersonic CFD will be the integrating agent in the design.

These comments do not imply that the existing hypersonic facilities, within NASA and elsewhere, are no longer of value for air-breathing vehicles. On the contrary, such vehicles will still present problems similar to those of the earlier rocket-propelled vehicles, and the present facilities, with some updating, can make important contributions in the following three areas:

1. Continuation of the materials and structures qualification testing that was initiated for the development of the Space Shuttle. The arcjets at the ARC and the 8-foot hightemperature tunnel in the Langley Research Center (LaRC) hypersonic complex are typical of facilities used in the Space Shuttle era to develop heat-protective materials and structural 
concepts. It is clear that further developments of this kind, and the facilities which support them, will be needed for air-breathing hypersonic vehicles.

2. Propulsion tests at the lower end of the flight corridor. Lewis Research Center (LeRC) has a 42-inch Hypersonic Tunnel Facility (HTF) designed specifically for propulsion testing up to Mach 7. LeRC now proposes to bring this back into service, with necessary modernization. The committee supports this action. Moreover, a larger propulsion facility, but with shorter-duration runs (15 to 120 seconds), can be obtained by simple modification of the LaRC 8-foot tunnel. This facility would be an extremely valuable addition.

3. Validation/calibration of hypersonic CFD codes. Although the true flight conditions may be beyond the range of the hypersonic wind tunnel at the highest temperatures and Mach numbers, comparison with experiments to validate or calibrate the codes under the attainable wind tunnel conditions is of great value. 



\section{4 \\ New or Updated Subsonic, Transonic, and Supersonic Facilities}

In the course of this study, the committee reviewed the NASA Task Team's survey of NASA subsonic, transonic, and supersonic facility needs and performed its own assessment. The committee considered the question of the adequacy of wind tunnel facilities for the design and development of a high-speed civil transport and other types of vehicles with cruise speeds up to Mach numbers of about 6. A number of good tunnel facilities are available for testing at supersonic speeds up to Mach numbers of 4 to 5 . Existing subsonic, transonic, and supersonic tunnels are considered to be generally adequate, with the exception of highReynolds-number capability and data productivity. The facilities available for testing in the Mach 6 region are marginal.

Although the existing supersonic tunnels are relatively small, with correspondingly small test Reynolds numbers, this is not a major concern for supersonic cruise designs unless some form of laminar flow control is employed. However, it is a concern where load data are to be obtained at relatively high angles of attack. The tunnels are not suitable for conducting laminar flow studies, and are not large enough to permit evaluation of integrated laminar flow systems for advanced supersonic transports.

The above findings led the committee to a series of recommendations. The following sections describe, in descending order of priority, the committee's recommendations for the development of new or improved NASA subsonic, transonic, and supersonic facilities.

\section{SUPERSONIC LOW-DISTURBANCE WIND TUNNEL}

The significant increase in friction drag, heat transfer rate, and thickness of the boundary layer accompanying the transition from laminar to turbulent flow is well known. The advantages of achieving a much greater extent of laminar flow over aircraft and spacecraft reentering the atmosphere have been repeatedly mentioned (Aeronautical Policy Review Committee, 1985, 1987). Performance and efficiency of aircraft from the Wright brothers' first Flyer to the Space Shuttle orbiter have been inhibited by the drag penalty of turbulent boundary layer flow, but the problem has assumed even greater importance in current studies of hypersonic airplanes. Both the production of thrust by air-breathing power plants and the drag (and heating) of these vehicles are critically dependent upon the state of the boundary layer, and positive thrust minus drag is not easily assured. It is also recognized 
that there is great uncertainty in predicting where transition will occur in many hydrodynamic and aerodynamic flows, unless some overriding factor, such as a boundary layer trip, is clearly dominant. Under different circumstances, all of which are commonly encountered, transitions can be brought about by different fluid dynamic processes, and each of these processes is the result of a combination of numerous, interacting environmental and configurational characteristics. Because of the practical importance of the problem, its diverse forms, and the enormous complexity that has prevented any solution, both experimental and theoretical research are expected to continue beyond the end of this century.

The discovery that boundary layers on models in supersonic wind tunnels are affected by disturbances radiated as sound waves from the edges of turbulent boundary layers on the wind tunnel nozzle walls was a major event. It led to a better understanding of the role of noise in boundary layer stability, and it shed more light on the puzzling discrepancies that had been noted earlier between transition data from different wind tunnels and flight. Following this discovery, the study of the fundamentals of transition on models in supersonic and hypersonic wind tunnels was largely curtailed because of the realization that experimental data would be contaminated by radiated noise. The disturbance is difficult to quantify, and it is even more difficult to analyze its effect on transition on a body in a wind tunnel. Unfortunately, the most direct way to preserve smoother laminar flow on wind tunnel walls is to operate at very low Reynolds numbers, but this approach runs counter to almost all of the other needs to be satisfied by the wind tunnel. In other words, the noise radiation can be reduced, but the resulting flow conditions are seriously degraded in value for almost all other aerodynamic testing uses.

In response to the situation briefly described above, NASA has, for some years, conducted research to determine how best to design a supersonic wind tunnel that would provide reasonably high Reynolds numbers in a test section that would not be contaminated by noise from turbulent wall boundary layers. This research, including experiments with a pilot tunnel, has led to the proposal that a supersonic low-disturbance wind tunnel be built. A description of the proposed facility has been given previously (Beckwith et al., 1986). A design Mach number of 3.5 and a nozzle exit size of approximately $20 \times 30$ inches are planned. The design will permit the use of other nozzles for Mach numbers of 2.5 to 6.0 , if that is necessary in the future.

With respect to the questions of size and simulation capabilities of the proposed wind tunnel, it is first noted that the size is compatible with a significant amount of existing equipment incorporated in the design. Both the high-pressure, high-temperature air supply system and the vacuum spheres for the exhaust of the tunnel already exist. Moreover, it has been estimated that a larger size would require operation at unit Reynolds numbers lower than typical full-scale free-flight values, in order to take advantage of the extent of laminar boundary layers made possible by the greater size.

Even though this facility would be three times larger than its pilot wind tunnel, it must be viewed as a research tunnel. Nevertheless, it is readily apparent that the proposed research facility is well justified. The present pilot wind tunnel is so small that it yields only a few inches of low-disturbance, streamwise flow at the higher unit Reynolds numbers. Thus, the range of operation under the desired conditions is severely curtailed.

Aerospace companies and government agencies concerned with the design of aircraft and missiles for flight at Mach numbers of 2.5 to 6 have urgent requirements for developmental testing of models under conditions that will enable the accurate prediction of boundary layer transition locations in full-scale flight. Therefore, demand for a still larger wind tunnel is very likely if the results of NASA research continue to be encouraging. The design 
features of a low-disturbance wind tunnel for developmental testing of aircraft to fly at Mach numbers above 2 can be clarified from studies with the proposed wind tunnel facility.

The proposed wind tunnel would provide a flow environment largely free of noise radiated from the nozzle walls and with reduced disturbances in the flow entering the nozzle, but there are other environmental and configurational factors known to affect transition. The subjugation of an unwanted factor, such as noise from nozzle walls, will allow investigators to focus on those factors that exist in the real operational flight environment. The gain in simulation capability represented by the suppression of radiated noise is a major achievement and an essential step in learning how to achieve larger areas of laminar flow over supersonic aircraft.

However, there is another point regarding simulation that should be noted. In view of the renewed interest in hypersonic aircraft, there is need for further research concerning transition in boundary layers on highly cooled surfaces, that is, where the wall temperature is less than about 30 percent of the stagnation temperature. Studies have been attempted in conventional supersonic wind tunnels, where the model surfaces were cooled with liquid nitrogen in order to achieve the desired wall temperatures. Unfortunately, this technique is now suspected to have caused undetected frost to form, creating roughness on the models, and it is uncertain whether the data at the lowest temperatures are trustworthy. This uncertainty is relevant because it identifies a research area that urgently needs to be investigated in the proposed wind tunnel and in flight experiments. To explore this phenomenon, it would be desirable for the tunnel to test models with surface temperatures as low as 10 to 30 percent of the stagnation temperature without incurring frost formation on the model. This aspect of the design criteria should be given due consideration. Both stagnation temperature and air dryness are of concern.

The technology involved in building this supersonic low-disturbance facility is straightforward; no risks associated with unproven concepts or increased scale are apparent, and the design goals should be attained. The great importance of boundary layer transition in the hierarchy of unresolved fluid dynamic problems justifies the recommendation that this wind tunnel be built. No other facility of this type is known to be in existence.

\section{LARGE-SCALE ACOUSTIC AND PROP FAN FACILITIES}

Comments from industry indicated that acoustic wind tunnel facilities are needed for both low-speed and high-subsonic/transonic investigations of rotors and prop fans. NASA has no capability for this type of investigation although such testing is considered essential. U.S. firms now go to the DNW wind tunnel facility in The Netherlands for such testing. This facility has a unique, large-scale acoustic test capability. Test section sizes and speeds are given in Table 4-1.

A comparison between options available at the U.S. facility and those at the DNW facility is given in Figure 4-1. The shaded areas represent the boundaries of the airflow, while the outer line shows the size of the surrounding test chamber.

Comments on the U.S. facilities shown in Figure 4-1 follow:

LaRC $4 \times \gamma$ meter-In addition to the chamber shown, the LaRC proposes to dig a trench under the test section to allow space for anechoic treatment below the airstream.

$A R C \quad 10 \times 80$ foot-The ARC $40 \times 80$-foot test section has a 6 -inch-thick perforated surface treatment, but since low-frequency noise is not significantly absorbed, frequencies below about 500 hertz require correction. In addition, out-of-flow noise measurements cannot be made with this configuration. 
TABLE 4-1 The Netherlands DNW Wind Tunnel Specifications

\begin{tabular}{lll}
\hline Test Section Size, $\mathrm{ft}$ & Velocity, ft/sec & Velocity, knots \\
\hline $31 \times 31$ & 200 & 120 \\
$20 \times 26$ & $270-360$ & $160-210$ \\
$20 \times 20$ & 475 & 280 \\
\hline
\end{tabular}

\section{DNW $6 \times 8$ METER}
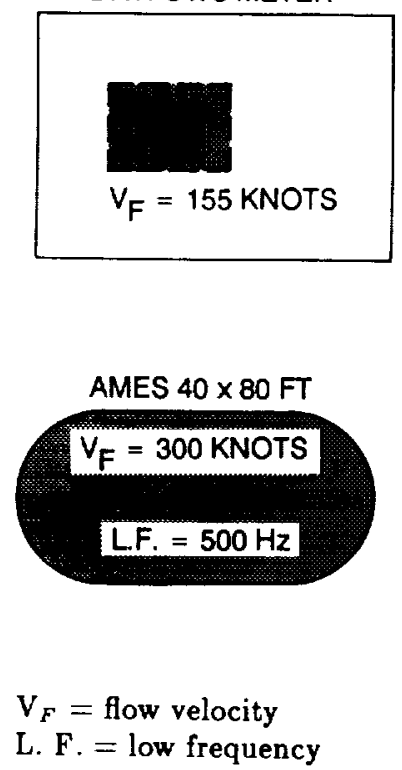

LANGLEY $4 \times 7$ METER

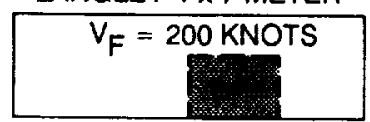

AMES $80 \times 120 \mathrm{FT}$

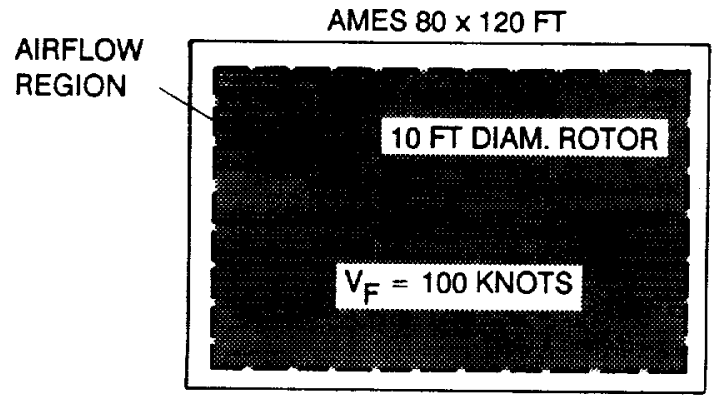

FIGURE 4-1 Comparison of wind tunnels for aeroacoustic studies. SOURCE: National Aeronautics and Space Administration.

$A R C 80 \times 120$ foot-Two options are being investigated for this tunnel. The one shown in Figure 4-1 involves treating the entire test section surface with absorbent wedges. The advantages are the comparatively low cost and flexible tunnel usage. The disadvantages are low tunnel speeds and an inability to accommodate microphones located outside the flow. A second option would be a "plug" in the test section to obtain higher velocities while using the existing section as an anechoic chamber.

Rotor noise has been a critical issue for rotorcraft manufacturers and users for decades. Reduced aircraft noise for civil applications is essential for both community acceptance and regulatory compliance. For future military rotorcraft which may depend on reduced observability for survival, the acoustic signature is one of the most difficult phenomena to 
deal with effectively. To understand and predict the sources of rotorcraft noise, a U.S. wind tunnel facility with the characteristics outlined in the following paragraphs would be highly desirable and may well be required.

The facility should accommodate a 10-foot-diameter rotor. Industry and government experience indicates that this is the minimum practical size from which good data can be obtained. Rotors of this size can also be fabricated with blades instrumented to measure pressure distribution to allow understanding of noise sources. A tunnel speed in the range of 270 to 340 feet/second ( 160 to $200 \mathrm{knots}$ ) is necessary to test rotors at the full-scale tip Mach number. Microphones need to be located at least two rotor diameters, and preferably four to five diameters, away from the blade tips to measure the far-field acoustic signature.

Ideally, the model and microphones should be located in a chamber with anechoic treatment that would allow measurements to be made down to a frequency of 50 hertz. This would permit measurements of the lowest full-scale frequencies of interest. A treatment of this type requires 10-foot-deep absorbent wedges on all surfaces. (Such a design is probably impractical, and the DNW's design, with 4-foot wedges, is a more realistic example.) Measured frequencies below the lower limit of the wedges might require correction.

It is desirable to locate the microphones outside the airflow to eliminate microphone wind noise interference. Although current rotors generate sufficiently high harmonic noise that the signal-to-noise ratio is not a problem even with microphones in the airflow, the very quiet rotors expected in the future may present difficulties. Measurement of broadband noise for either rotorcraft or fixed-wing craft requires that microphones be located outside the shear layer. Minimum tunnel ambient noise due to fans, motors, and so forth is particularly critical for broadband noise measurements.

Given the recognized importance of this research and technology (R\&T) activity for the achievement of quiet, high-performance rotorcraft, prop fan, and high-bypass, turbo fanpowered aircraft, the committee ranks the need for this wind tunnel facility as important. NASA must decide whether continued reliance on the DNW facility is acceptable or whether a U.S. facility should be developed.

\section{SUBSONIC LAMINAR FLOW DEVELOPMENT AND PRACTICAL APPIICATION}

Development of a new three-dimensional laminar flow wind tunnel was proposed to the NASA Task Team. Recommended characteristics included the ability to test at Mach numbers from low subsonic to transonic, quiet flow, high-Reynolds-number capability, threedimensional-model test capability, and an 8-foot tunnel size. Such a new wind tunnel was not included among the Task Team's recommendations. This committee concurs with its omission for reasons outlined in the following paragraphs. The committee does, however, have recommendations on how to conduct laminar flow control studies, and these are also included below.

Low-speed wind tunnel tests have contributed to the definition of laminar flow control (LFC) concepts and systems, but successful integration of all the complex elements of a LFC system and its successful demonstration require flight tests. In the X-21 program, the real sensitivities to wing shape and environmental contamination and the required fixes that allowed the X-21 to demonstrate extensive areas of laminar flow were only apparent in full-scale flight. The NASA Leading Edge Flight Test (LEFT) program was needed to demonstrate that the use of finely perforated wing skins (instead of slots) plus a highlift shield for environmental protection can assure reliable all-weather operation of LFC airplanes. Other flight tests have contributed to the development of the boundary layer 
stability theory for transition prediction, clarified the impact of engine noise on transition, and explored the limits of natural laminar flow on swept wings.

Moreover, the remaining tests required to bring LFC technology to the point of application in transport aircraft are only well suited to flight testing. These include verification of the hybrid* laminar flow control (HLFC) concept (that is, drag measurements), the design and verification of entire HLFC wings, and environmental testing.

One of the reasons that flight testing is more valuable than wind tunnel testing for LFC is the requirement for large-chord Reynolds numbers. The chord Reynolds number is much more important for laminar flow than for turbulent flow, because the degree of laminarization, and hence the drag benefit, has a first-order Reynolds number dependence. Even if it were possible to achieve the unit Reynolds numbers required for a reasonable model size, the suction system design would be impossible, because the size of the wing skin perforations (or slot widths) could not be reduced to the requisite scale. For valid wind tunnel testing, this leaves only airfoil tests with close to full-scale chords.

The extreme difficulty of the LFC airfoil experiment in the NASA 8-foot Transonic Pressure Tunnel (TPT) and the limited utility of the data from it are illustrative of the limitations of large-scale transonic wind tunnel testing for LFC. A tunnel liner was installed, with contours above and below the wing separately tailored for compatibility with the swept airfoil upper and lower surface profiles. A solid tunnel liner was necessary since the effects of the aerodynamic noise of a perforated liner on boundary layer instability waves are not well understood and would introduce a spurious, uncontrollable variable into the test. This need is not likely to change in the near future, because the directionality of the imposed sound field is important, as is its intensity and spectral content. The 8-foot TPT test apparatus cannot be used for exploring off-design angles of attack, inasmuch as this would destroy the two-dimensionality of flow for which the tunnel liner was so carefully designed. Moreover, at off-design Mach numbers, the difference in compressibility characteristics would also destroy the two-dimensionality of the flow.

The constraints imposed by use of a wind tunnel to conduct transonic LFC testing appear to be severe. However, if conditions do warrant such two-dimensional testing in the future, the 8-foot TPT (with ad hoc side wall changes) could again be employed.

Upon completion of current LFC testing, the NASA Task Team has recommended that the 8-foot TPT be upgraded with a data acquisition and display system that would permit efficient non-LFC testing of complete aircraft configurations, as well as with a new sting support that would allow a high angle of attack and sideslip testing. No new NASA facility could be provided sooner.

In summary, the committee believes that development of LFC systems for aircraft has now reached the point where NASA R\&D investment in flight testing and selective use of existing tunnels is preferable to capital investment in a new subsonic, three-dimensional, laminar flow wind tunnel. The committee feels that flight testing is a preferred alternative for the following reasons:

- Only flight testing can address three-dimensional wing and fuselage effects on LFC under appropriate conditions.

- Only flight testing can gather statistical data on the actual flight environment and the effectiveness of contamination avoidance and ice protection schemes.

*Hybrid laminar flow control is a technique in which leading edge suction is used in connection with natural laminar flow tailoring over the rest of the wing chord. 
- Only flight testing can explore off-design LFC characteristics of complete configurations.

- Only flight testing can achieve full-scale Reynolds numbers with hardware of the appropriate size.

- With flight testing, the spurious variable of free-stream turbulence is minimized.

- With flight testing, the noise environment is measurable and the directionality is better defined. More control exists.

- Existing facilities can accommodate two-dimensional R\&D tests that are suitable for a wind tunnel.

\section{THE LANGLEY VERTICAL FLOW SPIN TUNNEL}

In response to the questionnaire sent to industry and DoD by the NASA Wind Tunnel Study Task Team, a need was identified for a vertical flow spin tunnel with a dynamic pressure of at least 40 pounds per square foot and sized for 6-foot models.

While some of the support for such a facility stems from the fact that military aircraft have increased in size and wing loading since the Langley Vertical Flow Spin Tunnel was constructed in 1940, most of it arises from the twin thrusts for higher levels of agility and stealth. Many of the configurations currently under consideration are expected to have spin characteristics far worse than those of the more conventional aircraft flying today. A number of designers believe these characteristics will place severe limits on how far some of the concepts can be carried and feel there is a real need to be able to explore them early in the design stage.

Construction of the present Langley Vertical Flow Spin Tunnel started in 1940, and the tunnel was brought on line in 1941. It has a 20-foot-diameter vertical test section in which velocities of 90 feet/second can be achieved, giving Reynolds numbers of $600,000 /$ foot. Its primary function has been the study of spin characteristics, aerodynamics, and recovery techniques, although it has been employed to investigate the stability of various deceleration/delivery systems. Test techniques employ both free-spinning, dynamically scaled small models with the data primarily being optically recorded, and rotary balances, with the testing generally being conducted on larger models than those employed in the free-flight tests.

The data obtained from the free-spinning, dynamically scaled small models have always been viewed with considerable scepticism and used more as an indication of potential problem areas to watch for in flight tests than as an aid in the design process. Combined with the rotary balance data, however, the free-spin data have contributed over the last decade to a much better understanding of the phenomena involved.

The majority of work performed in the facility is requested by DoD, with proprietary investigations making up most of the rest. Only a very small amount of time is allocated for NASA in-house investigations. There currently is a considerable backlog of testing to be performed, and the tunnel is being operated at a level of two shifts a day.

The tunnel itself is in good physical condition. The drive motor has been refurbished three times since the initial construction of the tunnel: in 1955, 1978, and most recently, in 1984. The control room was improved as part of the 1978 refurbishment, and structural work was accomplished during the 1984 refurbishment. The staff has estimated additional updating would cost about $\$ 2.7$ million, including installation of a digital speed control system and variable-pitch fan, overhaul of the rotary apparatus, addition of a model attitude/rate sensor system, and addition of a high-resolution video cassette recorder system.

Although considerable strides have been made in refining the test techniques employed 
in the vertical flow spin tunnel, there is still a wide gap between the degree of assurance that a designer can place on the results of such spin tests and results from tests of the stability and performance characteristics of the design made in a more conventional tunnel. However, the vertical flow spin tunnel approach seems to be the only method of exploring spin characteristics short of actual flight testing, and these spin characteristics seem destined to become increasingly critical in future designs. Therefore, the committee encourages NASA to conduct a study with industry of the cost/benefit trade-offs between cooperative construction of a new, larger facility and modification of the present facility.

\section{EXHAUST NOZZLE TEST FACILITIES}

Anticipated advances in materials, structures, and analytical design methods have renewed interest in civil transport and military weapon system applications for the Mach 3 to 6 operating regime. However, there are a number of technologies that must be developed for both the airplane and the propulsion system before these applications become a reality.

The propulsion system for these applications will likely be a turbofan or turbojet for flight Mach numbers less than 4 and a turboramjet for Mach numbers greater than 4 . In addition to the various component technologies that are needed, there also is a requirement for test facilities in which ground testing in support of the development process can be conducted. A specific component of concern is the exhaust nozzle for high-Mach-number propulsion systems, and a nozzle static thrust stand is needed to develop design criteria and optimize performance.

The current and anticipated growth in interest in Mach 3 to 6 air-breathing propulsion systems requires that facilities be available to test and obtain performance data on exhaust systems up to the very high pressure ratios (and representative Reynolds numbers) associated with high-Mach-number operation. This is particularly true in view of the fact that the requirements for future high-Mach-number engine exhaust systems (relating to operating pressure ratio, amount of secondary flow, three-component force measurement, and instrumentation demands) exceed by a large margin the capability of current government nozzle test facilities.

A significant amount of design data already exists for turbomachinery and ramjet exhaust systems for Mach numbers up to 3, primarily for axisymmetric configurations and relatively simple two-dimensional concepts. Data applicable to the Mach number range of 4 to 5 are much more limited and are not adequate for the future high-performance turboramjets that will require multifunction exhaust systems.

At high flight speeds, a wide potential range of pressure ratio and exit area options exists due to design options relative to inlet total pressure recovery and bypass duct pressure loss. Because of this wide range of options, a significant amount of generic nozzle data is needed to guide the necessary design trade-offs between the exhaust nozzle and overall engine system. This type of design data for future propulsion concepts is a critical requirement.

With regard to facility capability, it is important to point out that the pressure ratio requirement for the high-Mach-number nozzle evaluations is an order of magnitude greater than that for current nozzle systems. The implication is that a very low back-pressure exhaust system will be required for a high-Mach-number nozzle test facility.

Another important aspect of the facility needs for high-Mach-number nozzle evaluation is the availability of high levels of secondary airflow. The inlet sizing for high-Mach-number engines is such that at the lower supersonic flight speeds a considerable amount of inlet airflow spillage exists. This condition can result in significant drag, particularly if the inlet operates subcritically. 
TABLE 4-2 Proposed Specifications for the Exhaust Nozzle Test Facility at the Langley Research Center

\begin{tabular}{lll}
\hline Current Facility & $\begin{array}{l}\text { First Step } \\
\text { (operational 1988/1989) }\end{array}$ & $\begin{array}{c}\text { Final Step Improvement } \\
\text { (operational 1992/1993) }\end{array}$ \\
\hline $\begin{array}{c}\text { Nozzle pressure } \\
\text { ratio of } 12\end{array}$ & $\begin{array}{c}\text { Nozzle pressure } \\
\text { ratio of 23 } \\
\text { 6-component force } \\
\text { balance }\end{array}$ & $\begin{array}{c}\text { Nozzle pressure } \\
\text { ratio of } 1,000 \\
\cdot\end{array}$ \\
& Heated air up to 3,000 $\mathrm{F}$ \\
& Secondary air as required \\
\end{tabular}

In order to minimize the drag liability and provide improved inlet airflow matching at flight speeds below the high-Mach-number design point, a bypass system is required. The bypass flow is most efficiently handled by passing the air through a duct to an ejector nozzle. The higher the design Mach number of the engine, the higher the range of flow capacity that will be required of the nozzle secondary flow system. In general, the secondary flow levels will be much higher than they are for current designs (by a factor of three or more), and consequently, the facility capability requirements for new systems must be adjusted accordingly.

The overall requirements are demanding. The high-Mach-number systems will require very accurate three-component force measurement, high secondary flow capability, verylow-pressure exhaust, and a significant instrumentation capacity. Currently, no government nozzle static test stands exist to develop and evaluate these systems.

At the present time, the only facility in the United States that has this capability is at Fluidyne, a private corporation. The committee believes that the national interest and need strongly indicate the desirability of having adequate high-Mach-number, air-breathing engine exhaust nozzle test facilities within NASA. It is understood that NASA's LaRC is proposing to modify its existing nozzle test facility to provide a fully adequate facility for high-Mach-number engine nozzles. Overall specifications for the proposed facility are shown in Table 4-2. The planned improvement in the nozzle test facility at Langley will more than satisfy anticipated requirements for a high-Mach-number engine nozzle test capability. The committee believes this proposed facility should be supported.

\section{OTHER PROPOSALS FOR NEW NASA FACILITIES}

The committee reviewed proposals for other new or improved subsonic, transonic, and supersonic facilities that it felt did not warrant as high a priority as those described in the previous sections. These additional proposals are summarized in Table 4-3, with committee comments included.

The committee's assessment of the large-scale, two-dimensional, transonic airfoil test facility proposal requires an additional explanation, since the great importance of airfoil 
TABLE 4-3 New Subsonic, Transonic, and Supersonic Facilities Suggested by Responses to NASA Task Team Survey, with ASEB Committee Comments

\begin{tabular}{|c|c|}
\hline Suggested Wind Tunnel Facility & Committee Comment \\
\hline Large-scale prop fan--propulsion & $\begin{array}{l}\text { Would be advantageous to have but not } \\
\text { an absolute need. }\end{array}$ \\
\hline Engine static test stand & $\begin{array}{l}\text { Industry is developing capability; no } \\
\text { government effort needed. }\end{array}$ \\
\hline $\begin{array}{l}\text { Large-scale subsonic propulsion/ } \\
\text { airframe integration }\end{array}$ & $\begin{array}{l}\text { Work apparently can be done by } \\
\text { AEDC/ASTF and NASA's } 40 \times 80 \\
\text { foot tunnel; no need for new } \\
\text { facility. }\end{array}$ \\
\hline $\begin{array}{l}\text { Full-scale subsonic/supersonic } \\
\text { free-jet inlet/engine propulsion } \\
\text { system verification }\end{array}$ & $\begin{array}{l}\text { Good suggestion, but capability } \\
\text { apparently being developed at } \\
\text { AEDC/ASTF. }\end{array}$ \\
\hline $\begin{array}{l}\text { Supersonic integrated propulsion/ } \\
\text { airframe }\end{array}$ & $\begin{array}{l}\text { Most work can be done at AEDC/ASTF } \\
\text { no need for new facility. }\end{array}$ \\
\hline $\begin{array}{l}\text { Large-scale, two-dimensional, } \\
\text { transonic airfoil test facility }\end{array}$ & $\begin{array}{l}\text { Considering expected CFD capabilities } \\
\text { and existing wind tunnels, facility } \\
\text { not justified. }\end{array}$ \\
\hline
\end{tabular}

\footnotetext{
AEDC $=$ Arnold Engineering Development Center

ASTF $=$ Aeropropulsion Systems Test Facility
}

design cannot be denied. It has been a major subject of aeronautical research since experiments on heavier-than-air flight began. However, the justification for the construction of a new large transonic wind tunnel for experimental development of two-dimensional airfoils seems questionable for the reasons given below.

It is noted that wind tunnels are not perfect tools, especially in the transonic area. Measured data are subject to the effects of various deficiencies such as flow nonuniformity, free-stream turbulence, blockage, and support interference; moreover, simulation of viscous flow phenomena is often inadequate. At hypersonic Mach numbers, additional deficiencies, such as the inability to duplicate real gas effects, are recognized. CFD now offers the means to calculate two-dimensional airfoil characteristics with precision comparable to those obtained in wind tunnel tests with the possible exception of drag characteristics (National Research Council, 1986). There is disagreement on the drag issue, with some CFD experts claiming that use of a computational grid of small enough size will overcome the inaccuracy in computed drag. On the other hand, an even greater computational grid density cannot disguise the fact that turbulence must be modeled in the computations and that turbulence models are a subject of continuing research.

It is important to keep in mind the rapid growth of CFD capability vis-à-vis the lengthy gestation time that characterizes the birth of new test facilities. The former capability should advance significantly in the minimum time period (at least 5 years) that would elapse before a new wind tunnel would come on line.

Finally, it is noted that there are several wind tunnels in the United States and abroad 
which seem reasonably adequate for research on two-dimensional airfoils. Existing tunnels where airfoil work is done include the $3 \times 7.5$-foot Low Turbulence Pressure Tunnel (subsonic) and the National Transonic Facility at the Langley Research Center, as well as the $5 \times 5$-foot National Aeronautical Establishment (NAE) tunnel in Canada. Other examples can be identified (Peñaranda and Fredar, 1985).

Considering the probable status of wind tunnel and CFD capabilities with regard to the development of airfoils in the 1990s, as well as the inventory of existing wind tunnels, the committee concluded that there is inadequate justification for proposing the construction of a new transonic wind tunnel for airfoil development. 



\section{5 \\ Hypersonic Facilities}

\section{GENERAL DISCUSSION}

Some representative hypersonic vehicle flight corridors are sketched in Figure 5-1. It should be noted that there is now interest in aircraft that would cruise at a design point(s) lying within the hypersonic, high-altitude area of this figure. Figure 5-2 presents the isentropic stagnation or reservoir temperatures and pressures corresponding to flight in the Earth's atmosphere. These two figures illustrate the central problem confronted by designers of hypervelocity, as opposed to merely hypersonic, aerospace test facilities.

However, the formidable reservoir conditions are only a part of the total problem when nonequilibrium real-gas processes arise. Then, not only the fluid properties but also the physical dimensions become significant, i.e., complete simulation demands full-scale size. Nonequilibrium air species processes typically become significant in high-speed flight above an altitude of approximately 50 kilometers $(160,000$ feet $)$. However, because hypersonic wind tunnels normally are operated with lower air densities than exist at equal Mach numbers in flight, some degree of nonequilibrium in wind tunnels operated at high temperatures is likely under all flow conditions.

Efforts to achieve the desired higher velocities and other flow conditions have not been lacking. However, work on that problem has been curtailed since the 1970 s. Direct means of energizing the wind tunnel testing medium, by means of electric arcs or by seeding and accelerating the medium through magnetohydrodynamics, leave the flow constituents and chemical process rates altered to a degree that has not yet been fully evaluated.

The relaxing of certain requirements can sometimes be acceptable if the objectives of specific tests are limited. For example, purely aerodynamic testing requires $\mathrm{Mach}$ and Reynolds number duplication and cold walls on the model, but it does not require temperature or enthalpy duplication if real gas effects can be ignored. For aerothermal testing, total temperature and pressure conditions and a scale suitable for the introduction of full-scale structural elements must be provided, but not necessarily full-scale Mach and/or Reynolds numbers. These temperature/pressure conditions are assumed to be known. Aeropropulsion testing, as of this writing, appears to require complete duplication of flow conditions and physical size.

While some compromises must be accepted so that experimental data can be obtained, 


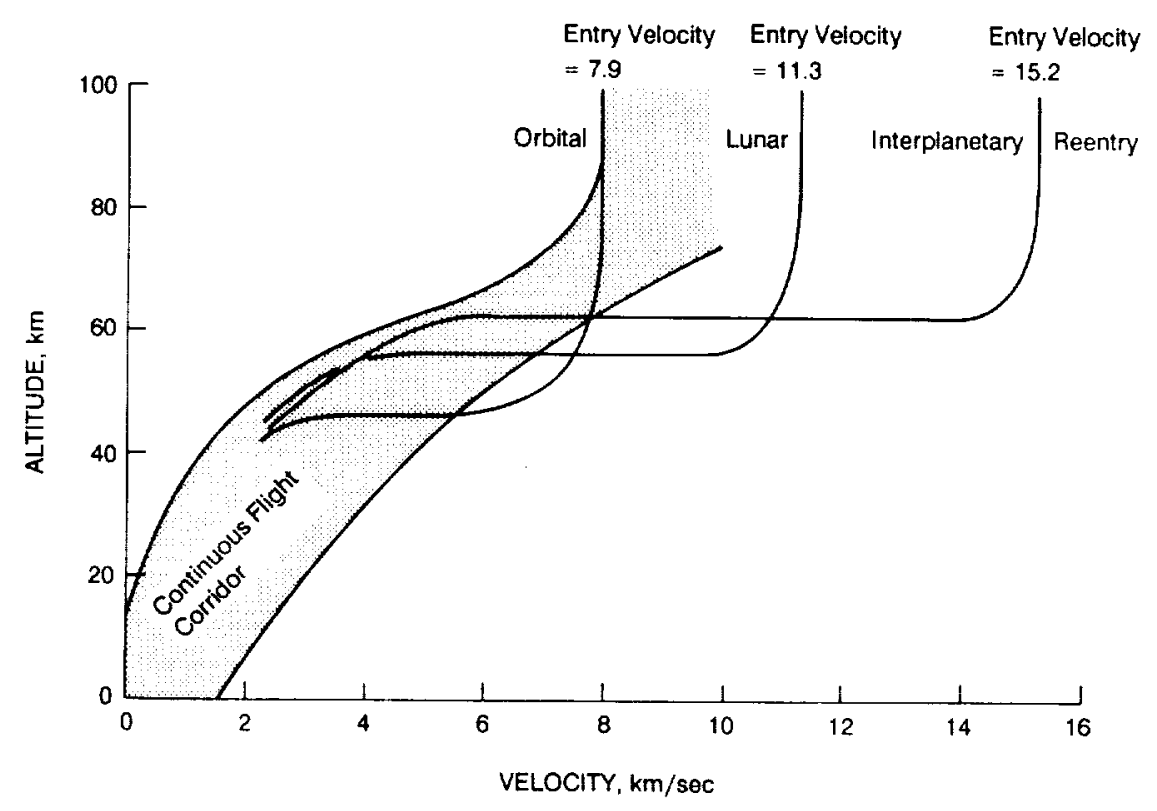

FIGURE 5-1 Typical manned lifting entry trajectories and continuous $\theta$ ight corridor in Earth's atmosphere. SOURCE: Adapted from Sullivan et al. (1969).

the serious deficiency in the simulation of flight conditions of existing hypervelocity experimental facilities cannot be ignored. It will become a greater handicap as air-breathing hypervelocity vehicles are developed. Thus, it may be said that the question of feasibility looms very large when hypervelocity facilities are considered, and the full complement of CFD, flight testing, seroballistics ranges, shock tubes, and all types of conventional and unconventional wind tunnels should be exploited as appropriate in test planning.

More detailed remarks on specific hypersonic wind tunnel categories and related facilities are presented in the following sections, in which the committee makes recommendations for research activities on specific types of hypersonic facilities.

\section{NEW OR UPDATED HYPERSONIC FACILITIES}

\section{Configuration Development Testing in the Mach 6 to 10 Regime}

There is an urgent requirement for laboratory facilities that will enable the efficient conduct of development test programs for integrated configurations of hypersonic aerospace vehicles under conditions that more fully simulate full-scale flight than the continuous flow wind tunnels now available permit. The three general types of testing considered are aerodynamic/aerothermodynamic, propulsion system integration (including internal flows with combustion), and structures/materials. Because of differences in the particular requirernents of these classes of testing and the compromises that may be accepted in striving 


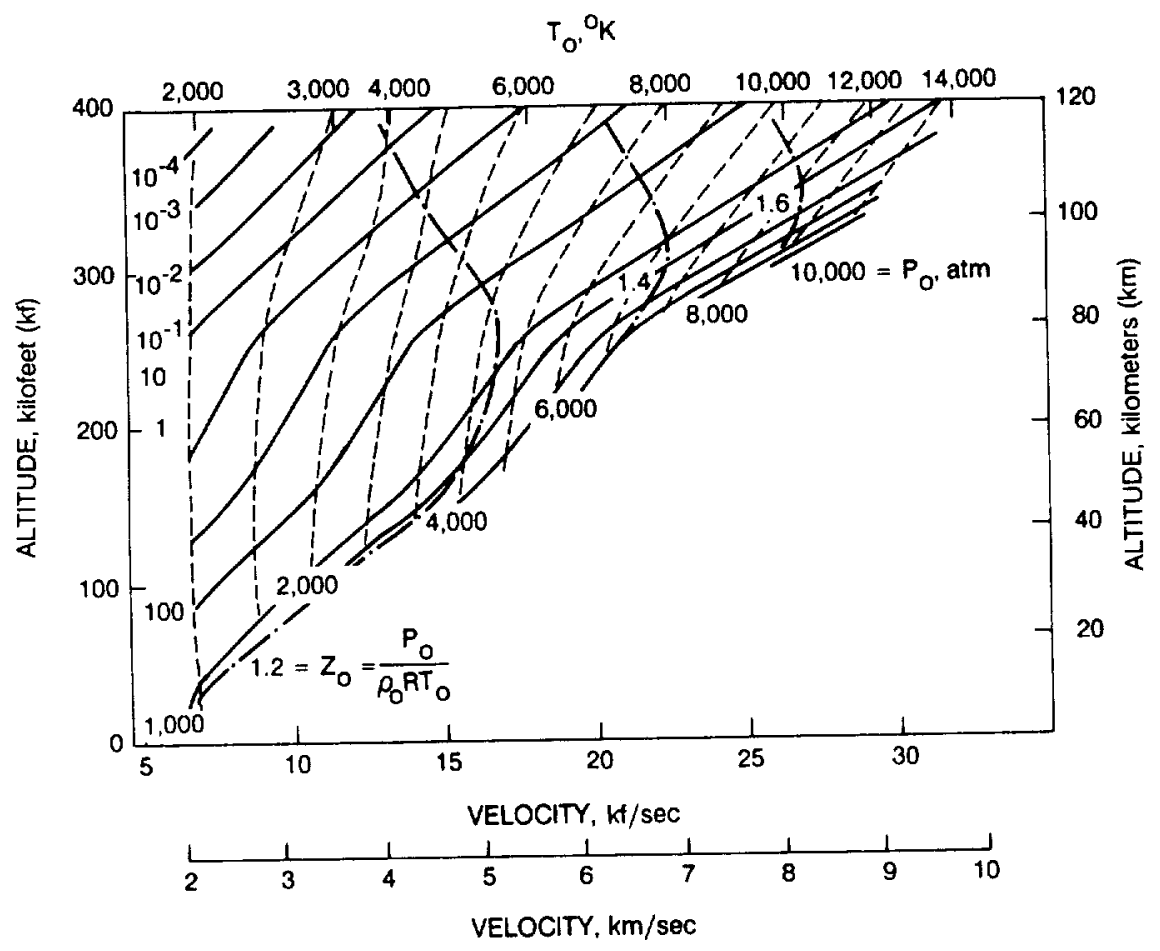

\footnotetext{
$P_{o}=$ stagnation pressure

$\mathrm{T}_{\mathrm{o}}=$ stagnation temperature

$\rho_{0}=$ stagnation density

$\mathrm{Z}_{\mathrm{o}}=$ compressibility factor

$R=$ gas constant
}

FIGURE 5-2 Equilibrium reservoir conditions necessery for flight duplication. SOURCE: Adapted from Lewis and Burgess (1969).

to satisfy those requirements, this section excludes discussion of structures/materials test facilities. That topic is discussed later in this chapter.

The formidable problems that arise when engineers attempt to build wind tunnels capable of duplicating the flight environment of typical hypersonic craft have been widely and exhaustively reviewed. The book by Nelson (1964), which is now over 24 years old, gives a good appreciation of these problems, reflecting the small progress that has been made since that time. A somewhat more recent review is available (Lukasiewicz, 1973). 
Since the Mach number 8 to 10 regime is where improvements in laboratory simulation capabilities are clearly needed and where the means seem to be available, there is reason to devote attention to that regime. The regime includes significant hypersonic flow phenomena, and it defines the current technological upper limit of flow simulation in the types of wind tunnels appropriate for configuration development programs.

Several types of tunnels that are already operational provide either near-perfect-gas, continuous flow, Mach 10 conditions at lower than desired stagnation pressures and enthalpies or real-gas (possibly nonequilibrium) Mach 10 conditions at desired stagnation conditions with an impulse or very-short-run-time mode of operation. In this discussion, impulse is taken to denote useful run times on the order of fractions of seconds. Tunnels with useful run times measured in seconds are designated intermittent or blowdown tunnels. The continuous flow facility offers high data productivity and relatively high data precision. The impulse tunnel offers only very low productivity and moderate data precision, but it can provide the desired hypersonic, cold wall, viscid-inviscid conditions. The real-gas feature, however, is of limited utility because simulation of flight conditions requires both thermo-chemical-kinetic equilibrium in the free stream and full-scale vehicle dimensions if appreciable nonequilibrium gas phenomena occur in the vehicle flow field. In flight at hypersonic Mach numbers, the nonequilibrium condition of air processes seems to be evident at altitudes above roughly 50 kilometers $(160,000$ feet).

It is feasible at this time to construct wind tunnels that duplicate total pressure and enthalpy in air corresponding to flight at Mach 10 at altitudes of 40 kilometers $(131,000$ feet), which is in the middle of the continuous flight corridor. Higher altitudes can also be simulated at Mach 10 . However, unless the tunnels are very large, with test section dimensions of several meters, the testing conditions will not allow Reynolds numbers to be as large as desired for the configuration development of complete hypersonic aerospace vehicles.

The different wind tunnel designs entail some compromises. The basic requirements that should be satisfied include the following:

- A high degree of simulation of the cold wall viscid-inviscid interaction and real-gas phenomena of the Mach 6 to 10 flight regime, plus low-disturbance flow for studying boundary layer transition. At this time, it is far from clear that the last condition can be met in any of the tunnel designs discussed in this section. It is a subject of continuing research. Therefore, the goal is assumed to be a free-stream flow of high uniformity and low disturbance levels, i.e., low vorticity, low temperature "spottiness," low noise, and low particulate contamination. Although low is not defined here, a quantitative sense may be conveyed by saying that it means much lower than that in hypersonic tunnels now in existence. Transition is discussed more fully below.

- High data precision, which depends upon quality of flow, thoroughness of flow diagnostics, and other conditions required for precise measurement.

- Large test section, broad range of unit Reynolds numbers, and acceptable level of data productivity for highly critical configuration development testing.

- Capability for operation at both high Reynolds numbers and very low Reynolds numbers so that the aerodynamics of flight at extremely high altitudes (70 to 100 kilometers) can be studied.

Satisfaction of all of these requirements in one type of facility does not now seem feasible. Facility types that satisfy some of the requirements are discussed below.

The conventional continuous flow tunnels are deficient in all respects except with regard 
to Mach number, productivity, and precision. An adequate number of these facilities already exist.

Intermittent or blowdown tunnels, which achieve higher stagnation pressures and enthalpies by heating air in large tanks partly filled with hot refractory pebbles or bricks, may have appreciably higher stagnation enthalpies than the continuous flow tunnels do. However, Mach 10 flight levels of total enthalpy are not attained, and productivity suffers because of the intermittent mode of operation. The addition of heat by burning fuels such as methane or hydrogen in the flow and then replenishing the depleted oxygen by injecting cold oxygen downstream of the burner is a means for reaching flight levels of total enthalpy. Unfortunately, a large amount of water is formed during this process, which appears to be a serious detriment to accurate measurements.

Continuous flow tunnels operated with nitrogen, electrically heated by graphite heating elements, can be made to match or exceed the stagnation conditions of the intermittent tunnels, but they are marginal, at best, with regard to enthalpy. When operated with nitrogen, they are near-perfect-gas tunnels. There is the possibility of mixing heated nitrogen with oxygen to produce air at approximately $2,400 \mathrm{~K}\left(4,000^{\circ} \mathrm{F}\right)$. Although this temperature is much lower than the total temperature of flight at Mach 10 (3,000 to 4,000 K), the conditions would be favorable for good viscid-inviscid simulation, well-calibrated flows, and high productivity.

Electric-arc-heated tunnels can attain very high temperatures or enthalpies, which makes this type of tunnel appealing. At the current state of the art, a maximum feasible total pressure of roughly 200 atmospheres limits unit Reynolds numbers of continuous or near continuous flow, arc-heated tunnels. There are some who believe that this pressure can be approximately doubled by further work. Aided by current and developing flow diagnostic techniques, this type of tunnel would offer most of the advantages of the continuous flow tunnels operated with nitrogen, plus flight levels of total enthalpy. It would also provide the opportunity to conduct experiments on real-gas phenomena, though probably not simulating real-gas conditions during flight because of nonequilibrium in the flow expansion process, contamination by the arc electrodes, and other non-flight flow qualities. The advantages of high attainable enthalpies and real-gas experimentation at least partly offset the deficiency in maximum achievable Reynolds number, which characterizes all continuous flow tunnels to some degree. Depending on size, the power requirement for a large, arc-heated tunnel could be several hundred megawatts.

Impulse-type tunnels offer the highest stagnation pressures and enthalpies, can be of large size, and appear to be generally superior for satisfaction of the given requirements in all respects except for productivity. Some flow quality and data precision issues with respect to impulse-type tunnels are arguable. Unfortunately, the versions of impulse-type tunnels that produce the most desirable stagnation conditions also have the shortest run times. Although it may be debated, it does not seem certain that the impulse-type tunnel would be suitable for configuration development test programs. It does appear to be a valuable tool for research and specialized testing, which would take advantage of its highend stagnation conditions and flexibility in Mach and Reynolds numbers. The impulse-type facility also offers the advantage of cold surface testing without extensive model cooling.

It is recommended that the electric-arc-heated tunnel be considered for the aerodynamic/aerothermodynamic and propulsion configuration development role for Mach numbers up to 10 . Actually, maximum Mach numbers of 20 or more would be attainable at low stream temperatures, and testing at Mach numbers above 10 undoubtedly would be conducted. As explained above, the continuous flow tunnel operated with nitrogen represents less risk but is more limited in its simulation capability. It could be regarded as 
a fall-back design if studies lead to the conclusion that the arc-heated tunnel is not the better solution. The electric-arc-heated tunnel has risks with regard to flow steadiness and contamination because of the arc-heating process. In the past, this has imposed a limitation on the maximum usable total pressure. However, by use of a settling chamber and careful design, it is thought that these adverse features can be controlled when the maximum enthalpy attainable from the heating process is not the goal.

The dual roles of the continuous flow tunnels operated with nitrogen and the electricarc-heated tunnels discussed above should not be neglected-that is, although total temperatures and pressures would match free-flight values only up to Mach numbers around 10, the facilities also would be available for testing in the Mach 20 regime, although at these high Mach numbers, it is not known how to simulate fully all the time-dependent processes occurring in such high-temperature flows. Thus, heavy use seems assured. The important supplemental roles of the higher-performance, impulse-type wind tunnel and the free-flight (or tracked) aeroballistics range obviously should be integrated into hypersonic test programs in order to realize the particular advantages offered by each type of laboratory facility. Free-flight testing should also be regarded as another option for hypersonic R\&D. In general, the older facilities may be used until more advanced wind tunnels are available, but updating would seem to be unjustified in cases where simulation of hypersonic flight conditions is inadequate.

\section{Boundary Layer Transition in Hypersonic Flow and Implications for Wind Tunnels}

Aerodynamic heating is the dominant aerothermal problem faced by designers of hypersonic vehicles. Skin friction drag and inefficiencies caused by boundary layers in inlets of air-breathing propulsion systems are also concerns. These all are affected in major ways by the transition from laminar to turbulent flow, so the performance, safety, and efficiency of hypersonic aerospace vehicles often will be critically dependent on the extent of laminar flow maintained in flight. The potential for achieving large areas of laminar flow seems to be a feature of hypersonic flows, but that advantage often has not been realized in practice, and the reasons remain obscure.

Neither the general importance nor the status of research on hypersonic boundary layer transition will be reviewed here. The practical significance has been emphasized in numerous publications, two of the most recent being the Aeronautical Policy Review Committee reports (1985 and 1987). The status of research is constantly changing and is a subject that is outside the scope of this report. A reasonably recent review is available (Reshotko, 1976), and an extensive sample of still more recent research is contained in Kozlov (1985).

Hypersonic flow conditions create extra difficulties when boundary layer transition is analyzed. Density and velocity fluctuations occur, extreme differences in temperatures across the boundary layer strongly affect its stability, large inviscid gradients transverse to the boundary layer arise, and there may be ablation of surface material to add to the complexity of the analysis. At this time, little is known about the influence on transition of real-gas thermo-chemical-kinetic processes and catalytic recombination of dissociated air species on vehicle surfaces. These are known as hypersonic phenomena, but their interrelation with transition is unknown.

It should be noted that transition in the classical two-dimensional flow, streamwise mode is not the only area of concern. Transition on aerospace vehicles may also be related to separated shear layer instability, crossflow instability, attachment line contamination, or Görtler instability. The mode by which transition occurs may vary with vehicle type, 
attitude, speed, altitude, or location on the vehicle. The great importance of transition in the context of hypersonic vehicle technology makes it highly desirable that engineers be able to determine the transition locations on new designs prior to full-scale flight.

The long history of research on boundary layer stability and transition is replete with examples of experiments where the particular laboratory conditions so profoundly affected the data that much of the general value of the data was lost. Even subsonic wind tunnels frustrate their users with subtle effects of noise and free-stream turbulence that are not yet fully understood. At the present time, it is thought, and experiments seem to confirm, that low noise, low stream vorticity, low temperature spottiness, and low stream particulate content are the chief requirements to be satisfied by a wind tunnel for studies of boundary layer transitions. The suppression of flow disturbances created by the combination of supersonic flow and turbulent (rough) boundary layers on the test section walls has been a serious problem that only recently has been attacked with some success. More information on these facility requirements can be found in Beckwith et al. (1986) and in the section Supersonic Low-Disturbance Wind Tunnel in Chapter 4.

A hypersonic wind tunnel with flow characteristics leading to a transition at the same Reynolds numbers that would be found in flight tests has not existed in the past. The NASA Supersonic Low-Disturbance Wind Tunnel described previously (Beckwith et al., 1986) promises to be such a facility, but it will be limited to Mach numbers of 6 or less, and it will be relatively small, with a test section lateral dimension of approximately 0.5 meter.

As presently perceived, a wind tunnel that is suitable for research on hypersonic boundary layer transition should not only have the low-disturbance, clean free-stream flow described above, but it should also be operable at Mach numbers of around 10 and allow experiments to be performed with model surface temperatures as low as one-fifth of the stagnation temperature without frost formation on the model. NASA should consider building a new, quiet hypersonic facility reaching Mach 10 if it does not prove possible to modify an existing tunnel to adequately represent boundary layer and flow conditions.

Until research clarifies how to achieve flight transition Reynolds numbers on models in a Mach 10 to 20 wind tunnel, it cannot be promised that a large configuration development hypersonic facility will give its users satisfactory data on transitions. Meanwhile, research with suitable, existing hypersonic wind tunnels should be supported. In particular, the conversion of one of these existing tunnels to a "quiet" version by suppression or shielding of wall disturbances, paralleling the current research on quiet supersonic tunnels (see Chapter 4), should be initiated. The tunnel selected for this purpose should have a flow of good quality* and not have features that would make it unduly expensive to modify to achieve low-disturbance flow. In addition, it should not be a large facility or a facility that is heavily scheduled for user tests. Since the same personnel and facilities to be used in the study of low-disturbance hypersonic wind tunnel design would also be appropriate for research on fundamental boundary layer stability and transition, the qualifications for transition research must be met by both the facility and its key personnel.

* The NASA 21-inch hypersonic tunnel at the Jet Propulsion Laboratory has the highest flow quality of existing hypersonic facilities; its continuous flow capability offers time to stabilize test section temperature conditions. The feasibility of its conversion for "quiet" tunnel operation should be examined. Alternatively, since higher Reynolds numbers could be obtained by a quiet test section added to the AEDC-GDF, NASA might prefer to leave this field of experimentation to the Air Force facility. 


\section{Testing in the Regime Above Mach 8 to 10}

A serious barrier to the design of vehicles with Mach numbers above 8 to 10 is the lack of adequate facilities to simulate fully the flow or provide the data needed to validate the computational techniques. This lack forces either considerable conservatism or high risk in the design of present and future high-Mach-number aerospace systems. Table 5-1 summarizes key hypersonic flight simulation requirements in simplified terms (excluding structures/materials test requirements, which are discussed in a later section). The requirements do not detail the required flow physics or fundamental problems which must be understood. For example, aerodynamics require the correct boundary layer conditions (laminar, transitional, or turbulent), a wind tunnel flow quality that makes the results comparable to flight, and a cold wall simulation. These requirements must be met before one can really evaluate real-gas effects, flow equilibrium, and chemical kinetics (which are temperature and pressure sensitive). The situation for hypersonic flight is considerably different from that for subsonic and low supersonic flight, where reasonable wind tunnel simulation of most of the key parameters can be undertaken and where CFD can be validated to a considerable degree.

The requirements for aerodynamic design, configuration optimization, and aerodynamic propulsion integration are difficult ones, but the most challenging problems are those of aeropropulsion simulation, where a high degree of accuracy is required in the prediction of net thrust minus drag for the vehicle. The duplication of pressure, temperature, Mach number, and velocity and scale for the propulsion system leads to consideration of very-largeflow facilities with high power requirements. At the same time, problems of flow composition, flow quality, adequacy of flight simulation, and instrumentation are not addressed in present facilities.

It is clear that near-term solutions to the full range of simulation problems are not available, although some areas can be addressed now, or it will be feasible to address them in the near term. The particularly difficult problems are associated with the high-Machnumber regime. Innovative solutions that give adequate flow simulation for some or all of the required parameters will require intensive and focused R\&D activity. Several concepts, which have been developed or explored in the past, hold possibilities of significant capability for testing above Mach numbers of 8 to 10 .

\section{Arc Heater}

As mentioned earlier, the arc heater has been suggested as the most likely candidate of the direct heating schemes because of its high reservoir temperature capabilities. A projected upper limit of flight simulation of about Mach 10 to 12 results from presently perceived reservoir pressure limitations of around 200 atmospheres. Flow composition concerns for propulsion testing at the high-Mach-number end of the spectrum have been addressed earlier in this report. Some degree of aerothermal simulation of high-speed flight can be achieved by tailoring the nozzle to match total temperature and pressure at the expense of Mach number simulation. However, for aeropropulsion simulation above Mach 12, some technique other than isentropic expansion of the gas must be sought to combat the nonequilibrium state of the gases entering the test section.

\section{Magnetohydrodynamic Accelerator}

Magnetohydrodynamic (MHD) acceleration of the heated gas, which is one way of adding energy to the stream, has been proposed for developing very-high-velocity flows. The 
TABLE 5-1 Simulation of Hypersonic Flight

\begin{tabular}{|c|c|c|c|c|}
\hline \multirow[b]{2}{*}{ Type of Test } & \multirow[b]{2}{*}{ Simulation Requirements } & \multicolumn{3}{|l|}{ Simulation Method } \\
\hline & & Duplicate & Relax & Facility Concerns \\
\hline Aerodynamic & $\begin{array}{l}\text { Reproduce force } \\
\text { coefficient, pressure } \\
\text { and heating } \\
\text { distributions }\end{array}$ & $\begin{array}{l}\text { Mach number, } \\
\text { Reynolds number }\end{array}$ & Temperature & $\begin{array}{l}\text { Real-gas effects, } \\
\text { flow equilibrium, } \\
\text { scaling }\end{array}$ \\
\hline Aerothermal & $\begin{array}{l}\text { Duplicate heating rates } \\
\text { and aeroshear, full-size } \\
\text { hardware }\end{array}$ & $\begin{array}{l}\text { Total tempera- } \\
\text { ture and } \\
\text { pressure }\end{array}$ & Mach number & $\begin{array}{l}\text { Flow composition, } \\
\text { test methods, } \\
\text { measurements }\end{array}$ \\
\hline Aeropropulsion & $\begin{array}{l}\text { Conditions for proper } \\
\text { chemical reactions, } \\
\text { mixing, boundary layers, } \\
\text { and shocks; full-size } \\
\text { hardware }\end{array}$ & $\begin{array}{l}\text { Pressure, } \\
\text { temperature, } \\
\text { mach number, } \\
\text { velocity scale }\end{array}$ & & $\begin{array}{l}\text { Pressure, size, } \\
\text { power, flow } \\
\text { composition, test } \\
\text { methods, } \\
\text { measurements }\end{array}$ \\
\hline
\end{tabular}

SOURCE: Taken from a presentation by the Amold Engineering Development Center, U.S. Air Force, to the Committee on Hypersonic Technology for Military Application, Air Force Studies Board. 
feasibility of the concept was verified through research accomplished nearly 20 years ago. The concept has the important advantage that the extremely high reservoir temperatures and pressures associated with isentropic expansion systems are not required. On the other hand, many technical issues must be resolved before large-scale application is feasible. Among these are MHD design scaling; channel wall heating and high-pressure operation; large power supplies for heaters, the electric field, and the magnet; and flow quality, including flow nonuniformity and effects of seed material. Considerable development (perhaps 4 to 10 years worth) will be required, but small-scale tests should be initiated as soon as possible to establish practicality and to provide estimates of the costs of providing the unique capabilities generated by this process.

\section{Ballistic Range}

An old solution for examining high-Mach-number flight is the high-performance ballistic range facility. Several facilities of this type have been in operation for many years and have provided important high-Mach-number data at comparatively high Reynolds numbers, but their small model size, coupled with the free-flight feature, has limited their capability for obtaining crucial data for many hypersonic flight problems. New studies and experiments have shown that an advanced, larger-scale facility is possible that would allow models of considerably greater weight and size than those that have been used previously. Either a rail gun or an induction accelerator concept has the potential for launching large-size models that would be subjected to a correct simulation of the aerodynamic and aerothermal environment at very high Mach numbers. The size of the model would permit extensive on-board instrumentation, and the scale of the vehicle would provide an external flow field which could be explored by ground-based, that is, stationary, instrumentation. Lifting configurations pose a further problem in controlling trajectory. However, if the launcher and measurement problems can be resolved, the facility would be extremely useful for aerodynamic and aerothermodynamic studies including real-gas effects, boundary layer transition, low-density flow, and chemical kinetics. Specific tests under optimum conditions would provide a valuable set of experiments for computational validation with the combination of on-board instrumentation and external flow instrumentation. However, propulsion system testing, including propulsion/airframe integration, introduces a higher level of complexity that may well be beyond the realm of possibility for ballistic ranges.

\section{Free-Piston Shock/Expansion Tunnel}

An interesting capability for high-Mach-number testing under appropriate conditions has been provided by the free-piston shock tunnel. This facility has the potential of generating the flight enthalpy, gas state, and gas composition needed for aeropropulsion testing, as well as for high-Mach-number aerodynamics studies. Serious consideration should be paid to the possible scaling up of this type of facility to the size required for reasonable aerodynamic and propulsion testing. This facility generates only very short test times, and careful consideration of the times required to develop the flows and to generate the fullscale chemical kinetics is important. The problem of simulating wall temperature effects may also be an important element in propulsion testing under these conditions. Several configurations of the free-piston shock tunnel have been proposed, each of which holds some promise in different areas of the hypersonic simulation problem.

In summary, there is at present no way to provide a complete simulation of aerodynamics and aeropropulsion systems at high velocities. Some elements of the problems can be studied 
with present or proposed facilities, and should be exploited for CFD validation in those areas. However, it is recommended that NASA take a fresh look at innovative concepts and extrapolation of past experience for the long-term solution. These concepts should be examined in pilot facilities as soon as possible to evaluate feasibility, assess scaling difficulties, and provide some basis for cost estimates.

In the near term (about 5 years), it is believed that the only reasonable approach is to concentrate on accurate measurements of aerodynamic and aeropropulsion flow fields within the capabilities of existing and upgraded facilities specifically designed to provide the basis for validating CFD codes. At the moment, CFD provides the only approach for estimating the performance of aerodynamic and aeropropulsion systems under high-Machnumber flight conditions. Confidence in the computations will only come from validation at the highest Mach numbers achievable in ground-based facilities and from flight experiments which, in turn, provide validation for the ground-based facilities and provide test data not currently attainable on the ground.

\section{THE ROLE OF CFD AND FLIGHT TESTING}

Although hypersonic wind tunnels are essential for obtaining test data on forces, moments, pressures, temperatures, and boundary layer transition, the actual flight conditions of velocity, pressure, and temperature cannot be obtained at Mach numbers above approximately 8 to 10 . Because the engine is so closely integrated with the airframe, the forces and moments must also be predictable while the engine is operating. Realistic test results for the scramjet power plant are even more difficult to obtain, because only when integrated with the airplane does engine performance have much meaning. Since burning length is an important engine parameter, results for subscale models of engines may be subject to large errors. No ground-based facility of sufficient size exists, or can be expected to be built in the near future, to test an adequately sized model of an aircraft with engines that operate at any hypersonic Mach number.

An alternative approach is to rely on CFD. CFD is a powerful discipline, but even CFD is dependent on a complete understanding of the physics of the boundary layer, mixing, and combustion. This understanding remains incomplete.

As understanding of the physics grows and CFD techniques are further developed, verification of the validity of CFD methods could be obtained by running CFD calculations for those hypersonic conditions obtainable in wind tunnels. If agreement is obtained, it would then give hope that CFD calculations for the higher velocities, pressures, and temperatures occurring in flight would be equally accurate. Because dissociation of air species is an increasing problem as temperature increases at higher speeds, there is a possibility that CFD methods might yield acceptable answers at lower Mach numbers, where tunnel verification is possible, and still be in serious error at higher Mach numbers.

The use of CFD to determine net thrust, by solving the complex dissociated gas combustion process and the interactions of the exhaust gases with the airframe, is the greatest challenge and has the greatest risk. Because net thrust is a small difference between a large gross thrust and a large inlet drag, even small errors (on the order of 1 to 2 percent) can have serious effects on determination of the final net thrust. Unfortunately, the complete verification of CFD thrust calculation results by tunnel testing is not feasible, although some components of engine performance, such as the combustion efficiency, can probably be determined from ground-based testing.

Thus, while CFD, verified where possible by hypersonic ground-based facilities, may 
provide answers up to some Mach number, final verification over the entire speed range of an orbital vehicle can only be found in flight tests.

\section{FACILITIES FOR STRUCTURAL TESTING}

\section{Hypersonic Vehicle Structural Requirements and Implications for Testing}

While the committee's charter emphasized wind tunnel facilities and its principal efforts have correspondingly been directed toward aerodynamics and propulsion issues, the committee believes it must also address materials and structures issues and related test facilities for hypersonic vehicles. This belief follows from the reality of the total integration of aerodynamics, propulsion, and structures at hypersonic speeds. Just as air-breathing hypersonic propulsion performance is sensitive to flow conditions over large areas of the airframe surface, so are heating and acoustic and pressure loading of the surface sensitive to the local laminar or turbulent state of the boundary layer and hypersonic flow field features.

In turn, the local characteristics of the boundary layer are very sensitive to both the global and local shape of the surface. Moreover, high and variable surface temperatures and loads, the widest possible use of hot structures to achieve the required very low structural mass fractions, the need for liquid hydrogen $\left(\mathrm{LH}_{2}\right)$ fuel, and the active cooling of some portions of the structure all ensure that deformations will change the local and/or global shape of the vehicle surface during flight. This aerothermoelastic behavior must be understood and accounted for in hypersonic vehicle design.

As an illustration of projected hypersonic vehicle structural requirements, the growing interest in air-breathing Earth-to-orbit and hypersonic cruise vehicles has highlighted the need for significant and fundamental design changes in future hypersonic vehicles from the designs developed for past space missions.

First, vehicle shapes will change to long, slender lifting body configurations, to provide a controlled, high compression of air entering the propulsion system inlets. Stagnation temperatures near the nose and lifting surface leading edges will pose fundamental design problems for such vehicles. Furthermore, the drop-off in boundary layer temperature next to the aircraft's outer skin with distance from these stagnation points is not so dramatic as to make materials/structural problems elsewhere on such vehicles inconsequential. Typical surface temperatures for a maneuvering reentry vehicle of the transatmospheric type, with a high cross-range capability from polar orbit, are predicted to range from around $2,030 \mathrm{~K}$ $\left(3,200^{\circ} \mathrm{F}\right)$ to around $530 \mathrm{~K}\left(500^{\circ} \mathrm{F}\right)$ on the centerline of the aircraft from the lower surface of the nose to the upper surface three quarters of the aircraft's length aft, respectively. For comparison, approximate useful upper limits of temperature for typical off-the-shelf metallic materials used in gas turbine engines and other applications are $1,800^{\circ} \mathrm{F}$ for Inconel $625^{\prime}$, $1,600^{\circ} \mathrm{F}$ for Rene 41 , and $800^{\circ} \mathrm{F}$ for boron/aluminum composite. Only carbon-carbon, used on the leading edges of the Space Shuttle, can withstand the stagnation temperatures of such vehicles.

Compared with the Space Shuttle, which sheds its structure as it proceeds to orbit, hypersonic, air-breathing vehicles will require a much greater efficiency of the combined structural and thermal protection systems. Although "hot structure" is clearly preferable to an insulated or actively cooled structure from a weight and complexity standpoint, a hot structure will not do the total job or even most of the job for hypersonic vehicles in the near future. Major developments will be required to arrive at structural designs that include thermal protection and/or active cooling of the structure and that will work, impose minimum weight penalties, and provide rapid turnaround. The tile passive insulation system 
provided by the Space Shuttle's outer surface of tile is a first-generation system that is not satisfactory with regard to the last of the three criteria given above, however successful it may be in other respects. Since hot structure will be used to the maximum possible degree, and at the same time, the hottest portions of the vehicle (sharp leading edges and engine structure) will likely require active cooling, thermal and mechanical effects on structure cannot be decoupled as they are in the Space Shuttle, and $\mathrm{LH}_{2}$ and gaseous hydrogen $\left(\mathrm{GH}_{2}\right)$ will coexist with the hot structure.

The severity of the above-mentioned requirements makes it clear that hypersonic structural testing facilities are necessary for the development of hypersonic air-breathing cruise or transatmospheric vehicles. Their use must be integrated with CFD analyses, aerodynamic wind tunnel tests, thermostructural analysis, and flight tests to define boundary layer flow characteristics, structural design requirements and performance, and vehicle performance.

\section{Existing NASA Hypersonic Structural Testing Facilities}

\section{Langley Research Center}

In the 1950 s and 1960 s, LaRC was the focal point of NASA research on high-temperature structures and thermal protection systems for high-speed flight in the atmosphere and for space vehicle reentry. Since the early 1970 s, much of Langley's high-temperature structures research has been a joint activity with the Dryden Flight Research Facility (DFRF) of the ARC. LaRC surplused antiquated high-temperature structures test equipment in the late 1970s and now conducts mostly basic R\&T to develop high-temperature structure concepts and analysis methodologies. Dryden handles most of LaRC's testing of large structural elements and components, including such functions as test methods definition, instrumentation, and test/analysis correlation.

LaRC, however, still operates one of NASA's major test facilities for determining the thermal and pressure loads on hypersonic vehicle engine and airframe structures: the 8-foot high temperature tunnel (HTT). The 8-foot HTT was activated in the mid-1960s and has been used for over 20 years for aerothermoload and aerothermostructure testing. It is a blowdown facility capable of 30 to 120 seconds of flow at a nominal Mach number of 7 through a test section 8 feet in diameter and 12 feet in length. Figure 5-3 is a schematic of the tunnel in which other facility dimensions are shown and a list of the currently available values of the operational parameters is included. The 8-foot HTT's current test medium, consisting of the combustion products of methane and air, will not support further combustion, and NASA wishes to expand its utility for propulsion testing. Therefore, a $\mathrm{C}$-of-F upgrade is under way to add $\mathrm{O}_{2}$ and nozzles for testing at Mach numbers of 4, 5, and 7. Operational parameters expected after this upgrade are listed in Figure 5-3. The current status of the facility and the planned modifications have been described in more detail by Reubush et al. (1987). The 8-foot HTT is still operational in its basic mode, but will be deactivated for approximately 1 year beginning in mid-1988 while modifications are undertaken. It is expected to resume research operations in April 1990 and will continue to include structures heating and loading tests among its uses.

Latent LaRC test capability includes an Actively Cooled Test Stand (ACTS) for combined loading and heating tests of structural panels cooled with circulating water-glycol solutions. The ACTS is currently located with the 8-foot HTT and will be moved before mid-1988 to one of two areas. At one location, its reactivation for tests with $\mathrm{LH}_{2}$ cooling is feasible and has been proposed, but not funded.

This restoration of the ACTS to active duty is one element of a LaRC-proposed Thermal 


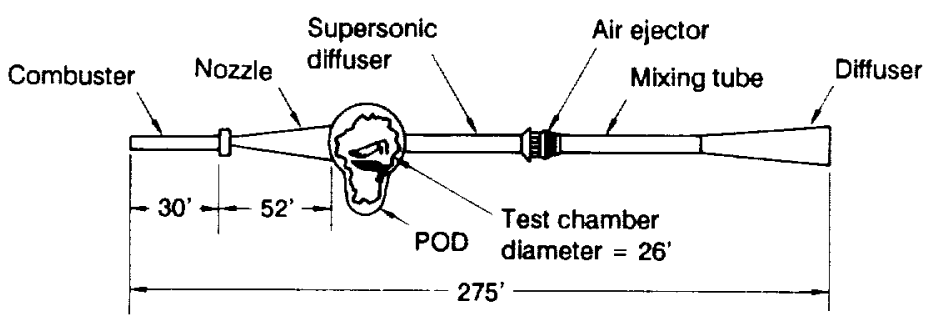

\section{TUNNEL CHARACTERISTICS}

Test medium: oxygen-enriched methane-air combustion gases

$\begin{array}{lrrr}\text { Mach numbers: } & 4 & 5 & 5.8 \text { to } 7.3 \\ \text { Reynolds number (million per foot): } & 2.5 & 1.4 & 0.3 \text { to } 2.2 \\ \text { Total pressure (psia): } & 155 & 270 & 150 \text { to } 2,400 \\ \text { Total temperature (deg R): } & 1,640 & 2,350 & 2,400 \text { to } 3,600 \\ \text { Dynamic pressure (psf): } & 1,650 & 1,285 & 250 \text { to } 1,800 \\ \text { Maximum test time (sec): } & 40 & 200 & 120 \\ \text { Simulated altitude (kft): } & 60 & 75 & 80 \text { to } 130\end{array}$

FIGURE 5-3 Schematic and operational characteristics of the Langley 8-foot high-temperature tunnel. SOURCE: National Aeronautico and Space Administration.

Structures Test Complex for use in a vigorous R\&T effort to prepare for future hypersonic vehicles. The cost of restoring and extending this test capability is projected by NASA to be about $\$ 2.5$ million.

LaRC also has operational a materials testing laboratory and has proposed a C-of-F expansion of this capability in fiscal year 1990 to support an accelerated effort in light alloys for future hypersonic vehicle airframes. The cost of this facility upgrade is projected by NASA to be $\$ 4.4$ million.

A new Thermal Acoustic Loads and Fatigue Research Laboratory has been proposed by LaRC as a C-of-F project in fiscal year 1990 . One of its test functions is simulation and measurement of thermal acoustic loads and the resulting structural response and fatigue life of panels subject to either a hypersonic jet or turbulent boundary layer at Mach numbers from 3 to 9 . A preliminary engineering report on the facility will be prepared in fiscal year 1988. NASA's estimate of the projected cost of this facility is $\$ 13$ million.

\section{Lewis Research Center-Plum Brook Station}

Three major facilities capable of thermostructural tests with $\mathrm{LH}_{2}$ or $\mathrm{GH}_{2}$ exist at the LeRC's Plum Brook Station. These are large, space vehicle development facilities that represent a major U.S. investment.

The Spacecraft Propulsion Research Facility (B-2) is shown in Figure 5-4 as it might be used to test NASP structural segments. It has a 38-foot-diameter, 55-foot-high stainless steel test chamber with a 27-foot-diameter access door at the top and a 20-ton bridge crane for test hardware assembly. It can sustain a vacuum environment to $10^{-8}$ torr or 


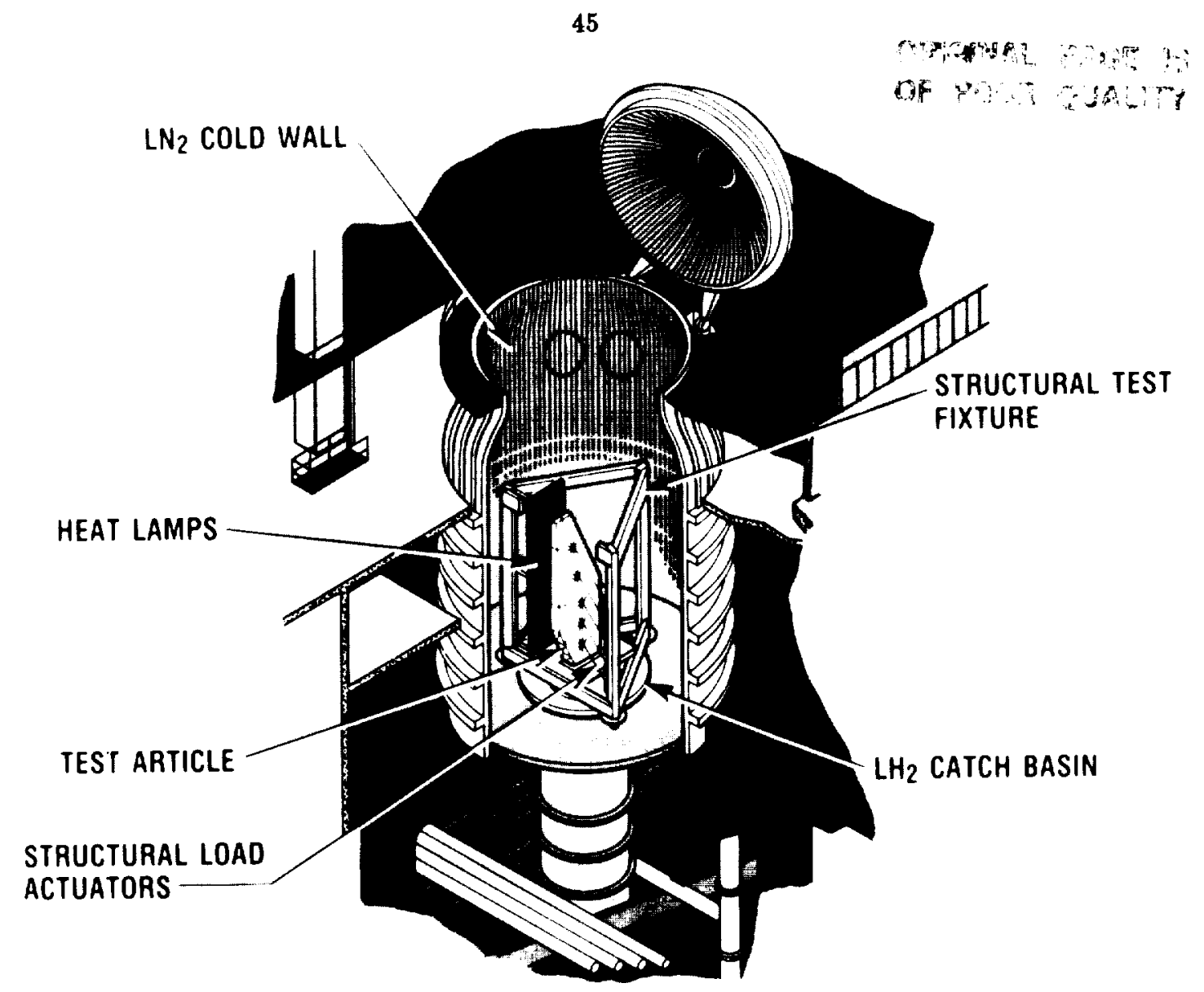

FIGURE 5-4 B-2 test facility structural test of NASP airframe section. SOURCE: National Aeronautics and Space Administration.

inert gas environments with positive pressure. It has a built-in cryogenic cold wall and a 56,000 -gallon $\mathrm{LH}_{2}$ storage capacity and is designed to handle $\mathrm{LH}_{2}$-fueled test articles safely. Its 15-megawatt reserve electric power for quartz lamp thermal simulation is expandable to 80 megawatts. It has a 250-ton floor load capability with hard points for structural load reactions.

The B-2 facility has been on standby and has had routine facility maintenance since 1974. A reactivation feasibility study in early 1987 found that all systems are in excellent condition and that estimated reactivation costs are $\$ 1.0$ million to $\$ 1.4$ million. The vacuum tank/system of this facility has already been reactivated. Additional funds are required for ancillary equipment to support structural testing.

A second major facility at the Plum Brook Station that is suitable for full- and large-scale structural testing is the Space Power Facility. This facility has the largest nuclear-rated, controlled-environment test chamber in the world-a 100-foot-diameter, 122-foot-high aluminum chamber surrounded by a heavy concrete enclosure. Structural test capabilities include temperature and structural load simulation; experience includes handling $\mathrm{GH}_{2}$ inside the chamber. Reactivation costs are estimated by NASA at \$4 million. Again, additional funding is required to support structural testing.

The third potentially useful Plum Brook Station capability for hypersonic structures 
testing is the so-called K-site: the Cryogenic Propellent Tank Lab. Designed to test cryogenic propellent tank insulation systems over a long time period, this facility has a 25-foot-diameter spherical test chamber, can simulate the space vacuum and temperature environment, and can handle experiments involving $\mathrm{LH}_{2}$. It features a shaker system for structural vibration tests. A reactivation study is currently under way. This facility should be useful for tests of hypersonic vehicle cryogenic tank structures.

LeRC has no current or planned structures R\&D that requires use of the above three facilities. Thus, their further reactivation in the near term will require the user to pay reactivation and modification costs and to provide most of the manpower for facility operation.

Plans for further reactivation of LeRC's Plum Brook Station facilities are limited to the fourth major facility at that site, the Hypersonic Tunnel Facility (HTF). The HTF is a blowdown facility providing true temperature, altitude, and air composition simulation at Machs 5, 6, and 7 in a 42-inch-diameter stream; it can handle $\mathrm{GH}_{2}$ - or $\mathrm{LH}_{2}$-fueled test articles. Reactivation and the addition of Mach 10 capability are proposed at costs of $\$ 4.6$ million and $\$ 5$ million, respectively. The HTF's principal use will continue to be propulsion tests with combustion, but it can be used for defining heat and pressure loading on scaled airframe structure as well as engine structure.

\section{Ames Research Center-Dryden Flight Research Facility}

The ARC-Dryden Flight Research Facility has NASA's only currently operational facility for thermostructural testing of large structural components, full-scale aircraft structures, and complete flight vehicles. The Flight Loads Research Facility (FLRF) was constructed in 1966 for combined loading and quartz lamp heating tests to simulate high-speed flight. It consists of a test area with a high bay, a 120 $\times 150$-foot reinforced floor, and anchor points for reacting test loads. There are adjacent support laboratories and a second-floor control room overlooking the test area. The FLRF's modern data acquisition and control system (DACS) has 1,280 data channels, includes numerous varied real-time data displays, and allows direct digital thermal control of $\mathbf{5 1 0}$ heating zones. This system allows three simultaneous test activities.

The FLRF cannot, however, safely accommodate tests with $\mathrm{LH}_{2}$, either in cryogenic tank simulations or in tests with active cooling. Dryden thus has proposed two new facilities: a Cryogenic Structures Test Apparatus (CSTA), to provide near-term; limited testing capability, and a major Liquid Hydrogen Structural Test Facility (LHSTF), to serve national needs for testing future large-scale hypersonic vehicle structures. A concept for the CSTA is shown in Figure 5-5. The facility would provide an initial test capability for $2 \times 2$-foot, actively cooled test panels under loading and under quartz lamp heating. Studies to define the facility, site, and required funding are under way. The goal is to have an operational facility in approximately 15 months, from time of approval.

The LHSTF would be the first phase in the proposed activation of a facility capable of ground-based tests of full-scale hypersonic vehicle structures that, with interrelated flight testing, are designed to provide confidence for structure qualification and hypersonic vehicle certification. While tests of full-scale, complete hypersonic vehicle structures would not be accommodated by this first-phase facility, it would be a complete laboratory for complex loading and heating tests that simulate flight mechanical and thermal loads on full-scale, large segments of the hypersonic vehicle structure. Tests would involve hot structures in the presence of cryogenic fluids, including $\mathrm{LH}_{2}$. The LHSTF was initially proposed for the C-of$F$ budget of fiscal year 1989 but has been resubmitted for fiscal year 1990 . Its definition and planning are well advanced (Dryden Flight Research Facility, 1987; National Aeronautics 


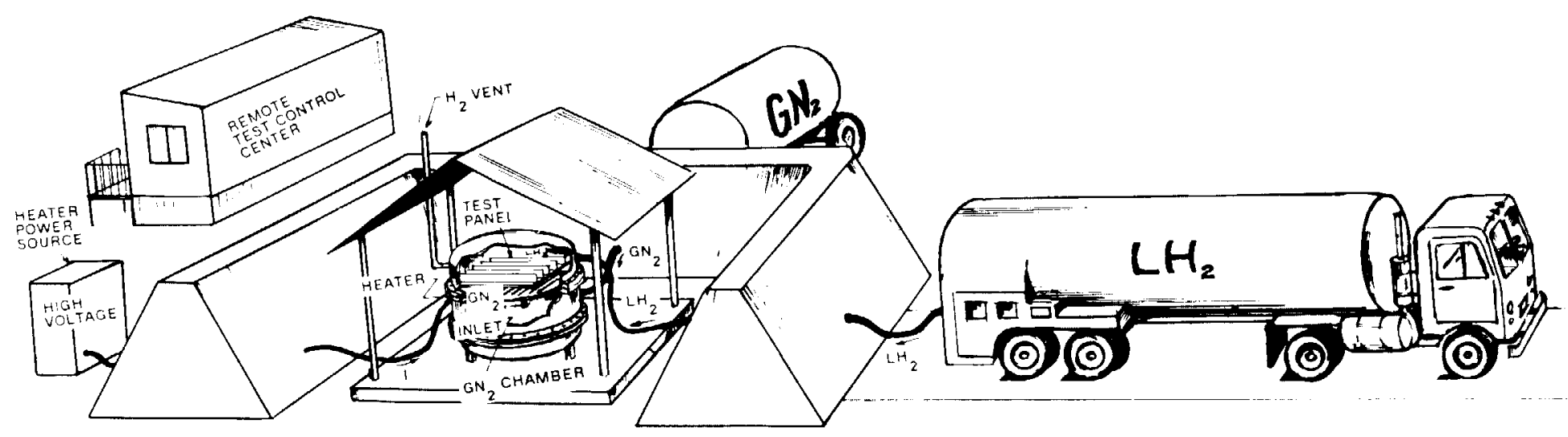

FIGURE 5-5 Cryogenic Structures Test Apparatus. SOURCE: National Aeronautics and Space Administration. 


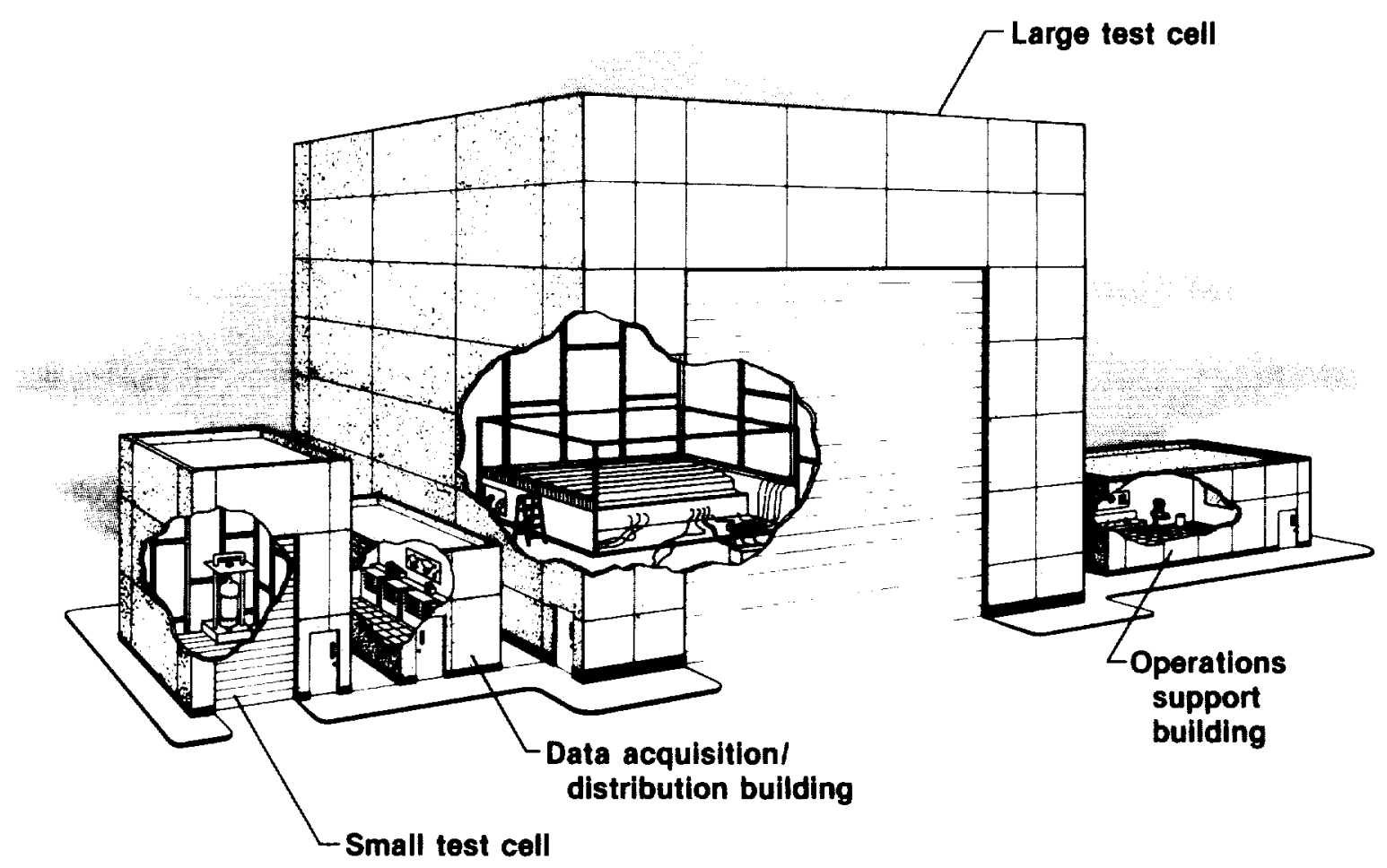

FIGURE 5-6 Liquid Hydrogen Structural Test Facility testing complex. SOURCE: National Aeranautice and Space Administration.

and Space Administration, 1987). Its cost is estimated by NASA to be $\$ 13$ million. This first-phase facility is intended to support LaRC's base R\&T efforts as well as DFRF flight tests.

The first-phase LHSTF is planned to consist of large and small test cells (Figure 5-6), with various support buildings for operations, data acquisition, and test control. For tests with $\mathrm{LH}_{2}$ or other cryogenic fuels, the test cell would be purged with an inert gas. Test personnel would operate from remote stations in the support buildings.

The LHSTF is intended to be a satellite of the ARC-Dryden FLRF and would be compatible with and use the existing test support capability of the FLRF as needed. In particular, the LHSTF would make use of the FLRF DACS. However, for safety reasons, its site would be at least 1,200 feet from the nearest occupied building or public road.

Finally, it should be noted that ARC's existing arcjet facilities and proposed additions are potentially useful for simulating airframe surface pressures and temperatures and the effects thereon of flow chemistry, especially in the hottest stagnation point areas of hypersonic vehicles.

\section{Committee Assessment and Comments Regarding Structural Testing Facilities}

The design, production, and operation of air-breathing hypersonic cruise and Earth-toorbit vehicles that are practical (that is, producible, cost-effective, productive, and reliable) clearly require significant technical advances in materials, structural and thermal protection concepts, and thermostructural analysis methods. These enabling advances in technology will not be produced in only a few years. Furthermore, they will not be achieved without 
a vigorous and stable $R \& D$ effort by experienced personnel with adequate test facilities for technology development and verification.

Such facilities are needed to advance understanding by means of two kinds of tests, which at this writing appear to be separable. The first is to determine local skin temperatures and pressures and surface chemistry effects. Such experiments are likely to require full Mach and Reynolds numbers and total enthalpy, as well as real-gas aspects and surface emissivities. It is not clear that anything other than scale can be relaxed in ground testing, and it is likely that the real operational structural environment will only be completely determined through actual flight tests. The second kind of test is to provide these skin temperatures and pressures on full-scale structural elements and determine the effect on the structure; here, Mach and Reynolds numbers are likely to be of little consequence. Because transient conditions are so likely to be important, however, heating rate and pressure time histories are likely to be part of the information desired in the first kind of test and part of the facility simulation capability required for the second.

While separable, both kinds of tests must be performed and the results related in a closed cycle by virtue of the sensitive dependence of boundary layer flow conditions on surface shape and motion and the dependence of surface deformation, in turn, on boundary layer transient pressures and resulting thermal gradients. Note that if true flow conditions at the highest Mach numbers are only achievable in flight, interrelated (perhaps alternate) flight and ground-based structural tests of complete vehicles will be required for structure qualification and vehicle certification.

Operational NASA materials and structures test facilities exist for support of the longterm R\&T efforts needed to achieve technology readiness for the operational hypersonic vehicles of the next century. However, their number and current condition, reflecting the near hiatus of such R\&T for the last 15 years, are obviously deficient. No operational NASA facility can currently support cryogenic cooling, heating, and loading test requirements for hypersonic structural components containing liquid hydrogen.

NASA center proposals for hypersonic structures-related facility modifications and additions properly recognize the need for a substantial increase in NASA's long-range-focused base R\&T and systems technology efforts. Proposed future facilities include one (the ARCDryden LHSTF) that is well-suited to support the nation's future need for demonstration, qualification, and certification testing. Since the LHSTF, even in its proposed (first-phase) form, will be operational too late for the NASP X-30 experimental transatmospheric vehicle, options for creation or actuation of near-term limited test capability are included in NASA center proposals. To assure that these long- and short-term facility proposals indeed meet national requirements, NASA has initiated a one-year study with five airframe companies to establish structural integrity certification requirements and corresponding test facility requirements.

NASA center facility proposals now need to be brought together in a central NASA plan for long- and short-term facility actions. The plan's definition, approval, and implementation with respect to early needs for NASP program support should not wait for completion of the above-mentioned one-year study.

The committee agrees that each of NASA's centers involved in materials and structures technology should have facilities for hypersonic materials and structures tests of specimens to the size of small structural components. These should include facilities for simultaneously applying flight loads and temperatures, with liquid hydrogen active cooling or simulated storage. The committee recommends approval of the pending center proposals that would accomplish this goal. 
For near-term development work, NASA should complete the reactivation of the LewisPlum Brook Station test facilities with minimum required changes and additions. While NASA Plum Brook Station personnel would presumably need to oversee and operate the facility, the industrial user could be responsible for personnel and equipment to conduct the tests.

For long-term support of the DoD and industry in development, qualification, and certification of hypersonic structures for future cruise and transatmospheric vehicles, NASA should proceed with construction and activation of the Liquid Hydrogen Structural Test Facility at the ARC-Dryden Flight Research Facility. This recommendation recognizes the established activity, staff, and related facility (i.e., FLRF) at Dryden; the probable utilization of Dryden for flight testing of air-breathing hypersonic vehicles; and the probable need for the facilities in place at the LeRC-Plum Brook Station facility for future long-term tests of Space Station structures. Toward the same end, NASA should also proceed with construction of the LaRC-proposed Thermal Acoustic Loads and Fatigue Research Laboratory, if such a step is supported by the current examination of test facility requirements that NASA has initiated with five airframe companies. 


\section{References}

Aeronautical Policy Review Committee. 1985. National Aeronautical R\&D Goals-Technology for America's Future. Washington, D.C.: Office of Science and Technology Policy.

Aeronautical Policy Review Committee. 1987. National Aeronautical R\&D Goals-Agenda for Achievement. Washington, D.C.: Office of Science and Technology Policy.

Beckwith, I., F. Chen, and T. Creel, Jr. 1986. Design Requirements for the NASA Langley Supersonic Low-Disturbance Wind Tunnel. AIAA Paper No. 86-0763-CP. Presented at AIAA 14th Aerodynamics Conference, West Palm Beach, Fla., March 5-7, 1986. Washington, D.C.: AIAA.

Dryden Flight Research Facility. 1987. Preliminary Engineering Report for the Liquid Hydrogen Structural Test Facility, NASA Ames Research Center (ARC), Dryden Flight Research Facility (DFRC), Edwards, CA. 93523, July 1987. Edwards, Calif.: Dryden Flight Research Facility. (Published based on a Facility Concept Study performed under Contract NAS2-12215 by PRC Systems Services, Aerospace Systems Division of Cocoa Beach, Fla.)

Dwoyer, D., P. Kutler, and L. Povinelli. 1987. Retooling CFD for hypersonic aircraft. Aerospace America 25(10):32

Kozlov, V., ed. 1985. Laminar-Turbulent Transition. New York: Springer-Verlag.

Lewis, C., and E. Burgess III. 1969. AEDC-TDR 64-214. Arnold Engineering Development Center, Oh.

Lukasiewicz, J. 1973. Experimental Methods of Hypersonics. New York: Marcel Dekker.

National Aeronautics and Space Administration. 1987. Ames Research Center Liquid Hydrogen Structural Test Facility, White Paper (Proposed Facility for Ames-Dryden). September 1987. Washington, D.C.: National Aeronautics and Space Administration.

National Research Council. 1983. Influence of Computational Fluid Dynamics on Experimental Aerospace Facilities. Committee on Computational Aerodynamics Simulation Technology Developments. Washington, D.C.: National Academy Press.

National Research Council. 1984. Aeronautics Technology Possibilities for 2000: Report of a Workshop. Workshop on Aeronautical Technology: A Projection to the Year 2000. Washington, D.C.: National Academy Press.

National Research Council. 1985. Aeronautical Technology 2000: A Projection of Advanced Vehicle Concepts. Panel on Vehicle Applications. Washington, D.C.: National Academy Press.

National Research Council. 1986. Current Capabilities and Future Directions in Computational Fluid Dynamics. Committee to Assess Current Capabilities and Future Directions in Computational Fluid Dynamics. Washington, D.C.: National Academy Press.

Nelson, W., ed. 1964. The High Temperature Aspects of Hypersonic Flow. Elmsford, N.Y.: Pergamon Press.

Peñaranda, F., and M. Freda. 1985. Aeronautical Facilities Catalogue, Vol. 1: Wind Tunnels, RP-1132. Vol. 2: Airbreathing Propulsion and Flight Simulators, RP-1133. Washington, D.C.: National Aeronautics and Space Administration. 
Reshotko, E. 1976. Boundary-layer atability and transition. Pp. 311-349 in Annual Review of Fluid Mechanics, Vol. 8, M. Van Dyke, W. Vincenti, and J. Wehausen, eds. Palo Alto, Calif.: Annual Reviews, Inc.

Reubush, D., R. Puster, and H. Kelly. 1987. Modification to the Langley 8-Foot High Temperature Tunnel for Hypersonic Propulsion Testing. AIAA Paper No. 87-1887 presented at The AIAA/SAE/ASME 23rd Joint Propulsion Conference, San Diego, Calif. June 29-July 2, 1987. Washington, D.C.: AIAA.

Sullivan, E., et al. 1969. Proceedings of $15 \mathrm{th}$ Annual Meeting of the Institute of the Environmental Sciences, Anaheim, Calif.

Wind Tunnel Study Task Team, National Aeronautics and Space Administration. 1987. Assessment of NASA's Major Wind Tunnel Facilities with Respect to Current and Future National Needs. Washington, D.C.: National Aeronautics and Space Administration. 


\section{Acronyms and Abbreviations}

$\begin{array}{ll}\text { ACTS } & \text { Actively Cooled Test Stand } \\ \text { AEDC } & \text { Arnold Engineering Development Center } \\ \text { ARC } & \text { Ames Research Center } \\ \text { ASEB } & \text { Aeronautics and Space Engineering Board } \\ \text { ASTF } & \text { Aeropropulsion Systems Test Facility } \\ \text { CFD } & \text { Computational Fluid Dynamics } \\ \text { C-of-F } & \text { Construction of Facilities } \\ \text { CSTA } & \text { Cryogenic structures test apparatus } \\ \text { DACS } & \text { Data Acquisition and Control System } \\ \text { DFRF } & \text { Dryden Flight Research Facility } \\ \text { DNW } & \text { Deutsch Neiderlandischer Windkanal } \\ \text { DoD } & \text { Department of Defense } \\ \text { FLRF } & \text { Flight Loads Research Facility } \\ \text { GDF } & \text { Gas Dynamics Facility } \\ \text { GH } & \text { Gaseous hydrogen } \\ \text { GN } & \text { Gaseous nitrogen } \\ \text { HLFC } & \text { Hybrid laminar flow control } \\ \text { HTF } & \text { Hypersonic Tunnel Facility } \\ \text { LaRC } & \text { Langley Research Center } \\ \text { LEFT } & \text { Leading Edge Flight Test } \\ \text { LeRC } & \text { Lewis Research Center } \\ \text { LFC } & \text { Laminar flow control } \\ \text { LH } & \text { Liquid hydrogen } \\ \text { LHSTF } & \text { Liquid hydrogen structural test facility } \\ \text { LN } & \text { Liquid nitrogen } \\ \text { MHD } & \text { Magnetohydrodynamic } \\ \text { NACA } & \text { National Advisory Committee for Aeronautics } \\ \text { NAE } & \text { National Aeronautical Establishment (Canada) } \\ \text { NASA } & \text { National Aeronautics and Space Administration } \\ \text { NASP } & \text { National Aerospace Plane } \\ & \end{array}$



NRC National Research Council
R\&D Research and development
R\&T Research and technology
TPT Transonic Pressure Tunnel
USAF United States Air Force
VSTOL Vertical and short takeoff and landing 


\section{Appendix A \\ List of Participants}

\section{NASA REPRESENTATIVES}

NASA Headquarters

Randolph Graves

Arthur Henderson

Duncan McIver

Cecil Rosen

Jack Suddreth

L. Michael Weeks

Louis Williams

Ames Research Center

James Arnold

Nancy Bingham

Dale Compton

Lado Muhlstein

Leroy Presley

Jet Propulsion Laboratory

Virendra Sarohia
Langley Research Center

Richard Barnwell

Lee Beach

Sidney Dixon

C. L. W. Edwards

Delma Freeman, Jr.

Wayne McKinney

Lewis Research Center

David Bowditch

Frank Kutina

NASA Task Team

Russell Hopps, Chairman

Milton Beheim

William Hamilton

Gerald Kayton

William Koven 


\section{DEPARTMENT OF DEFENSE}

Arnold Engineering

Development Center

James Mitchell

John Rampy
Defense Advanced Research Projects Agency/National Aerospace Plane

George Baum

Robert Craft

Wright-Patterson Air Force

Base/National Aerospace Plane

Leonard Pohlar

Walter Sefic

\section{OTHER ORGANIZATIONS}

CALSPAN

Paul Marrone

Charles Wittliff

General Electric

Daniel Harshman
ORI, Inc.

Randy Soderholm 


\section{Appendix B \\ Committee's Statement of Task}

The objective of the committee is to identify future major national aeronautical facility requirements and the status of current facilities to satisfy the projected requirements. In the process identify what needs to be done with existing facilities, and the need for new facilities to satisfy projected requirements. Concentrate on NASA facilities taking into consideration other government and industry facilities. Identify those actions required to provide the future capabilities considered most important.

The plan, in response to the objectives identified by NASA, will be carried out by the ASEB committee through:

1. Assessing the expected national demand for wind tunnel testing in terms of types of facilities and the extent of testing required, while being cognizant of the influence of computation methods on wind tunnel testing.

2. Reviewing NASA, other government, and industry assessments of the adequacy of major national wind tunnels to meet projected test demand. The review will include the need for rehabilitation and upgrading of facilities and consider the need for new facilities for test conditions not obtainable in present facilities even if modified.

3. Assigning priorities to various wind tunnel facility actions in broad categories such as "critical," "very important," "moderately important," or "no longer useful."

The basic data for the study is to be provided by NASA through a special study team chartered by NASA. 
